\title{
Current technologies and considerations for drug bioanalysis in oral fluid
}

Drug oral fluid analysis was first used almost 30 years ago for the purpose of therapeutic drug monitoring. Since then, oral fluid bioanalysis has become more popular, mainly in the fields of pharmacokinetics, workplace drug testing, criminal justice, driving under the influence testing and therapeutic drug monitoring. In fact, oral fluid can provide a readily available and noninvasive medium, without any privacy loss by the examinee, which occurs, for instance, during the collection of urine samples. It is believed that drug concentrations in oral fluid may parallel those measured in blood. This feature makes oral fluid an alternative analytical specimen to blood, which assumes particular importance in roadside testing, the most published application of this sample. Great improvements in the development of accurate and reliable methods for sample collection, in situ detection devices (on-site drug detection kits), and highly sensitive and specific analytical methods for oral fluid testing of drugs have been observed in the last few years. However, without mass spectrometry-based analytical methods, such as liquid chromatography coupled to mass spectrometry (LC-MS) or tandem mass spectrometry (LC-MS/MS), the desired sensitivity would not be met, due to the low amounts of sample usually available for analysis. This review will discuss a series of published papers on the applicability of oral fluid in the field of analytical, clinical and forensic toxicology, with a special focus on its advantages and drawbacks over the normally used biological specimens and the main technological advances over the last decade, which have made oral fluid analysis of drugs possible.

Drug detection in oral fluid specimens was used for the first time in the late 1970s, for the purpose of therapeutic drug monitoring [1]. Since then, oral fluid analysis has increased enormously, as can be seen by the increase in the number of publications on this matter over the past few years. This coincided with the development of more sensitive and reliable analytical equipment. However, these advances in technological resources were not solely responsible for this situation, as will be discussed further. Indeed, the unique properties of oral fluid and its advantages over other biological matrices played a very important role.

Advantages of oral fluid testing include the fact that the sample is collected noninvasively under direct supervision and without loss of privacy, reducing the risk of an invalid specimen being provided or sample adulteration and/ or substitution [2]. Furthermore, it is thought that saliva drug concentrations can be related to free drug concentrations in plasma and, consequently, to the pharmacological effects of drugs [3].

On the other hand, drugs that are ingested orally, as well as those that can be smoked, may be detected in high concentrations in oral fluid following recent use, due to residual amounts of drug remaining in the oral cavity [4-8]. Therefore, results for these substances may not be accurate because the drug concentration found in the oral fluid may not reflect the blood drug concentration.

Another important disadvantage of studying oral fluid is that examinees are sometimes unable to produce sufficient amounts of material for analysis [2].

For a better understanding of the increasing importance of this biological specimen on bioanalysis, as well as the need for sensitive techniques, this review will briefly discuss oral fluid physiology and the underlying mechanisms of drug incorporation. In addition, collection devices, detected substances and fields of application will be reviewed. Finally, the available analytical techniques for drug detection in oral fluid will be outlined, since their application represents the main goal of this paper.

\section{Physiology \& mechanisms of drug incorporation}

The terms oral fluid and saliva are often used in an interchangeable manner to designate the same biological specimen. However, oral fluid is the liquid sample obtained from the oral cavity, and constitutes a number of secretions from several

\section{E Gallardo', M Barroso² \& JA Queiroz ${ }^{1 \dagger}$ \\ ${ }^{\dagger}$ Author for correspondence \\ 'Centro de Investigação em \\ Ciências da Saúde, Universidade \\ da Beira Interior, 6201-506 \\ Covilhã, Portugal \\ Tel.: +35I 275329002 \\ Fax: +35I 275329099 \\ E-mail: jqueiroz@ubi.pt \\ ${ }^{2}$ Instituto Nacional de Medicina \\ Legal - Delegação do Sul, Rua \\ Manuel Bento de Sousa, 3, \\ II50-219 Lisboa, Portugal}

Oral FLuid

Alternative biological specimen, extremely useful for the assessment of drug-impaired driving 
sources [8], including saliva. In fact, three pairs of major salivary glands (parotid, submaxillary and sublingual), as well as an estimated 450-750 minor accessory salivary glands (situated on the tongue, the buccal mucosae and the palate) and oro-naso-pharyngeal secretions, contribute to some extent to its production. Therefore, oral fluid is generally accepted as a more accurate definition of this mixture of fluids [9].

Oral fluid contains the same electrolytes that are present in other body fluids, including water (99\%) and mineral salts. Proteins (mucins) and some enzymes for digestion are also present, but at very low levels. This sample is hypotonic compared with serum, although its ionic concentrations are not constant due to the circadian rhythm.

The $\mathrm{pH}$ of oral fluid is approximately 6.8 , but it can be higher in the case of an increase in the salivary flow. In this situation, its $\mathrm{pH}$ can even be greater than that of plasma [10].

An adult can produce as much as $1000 \mathrm{ml}$ oral fluid per day, and typical flows are approximately $0.05 \mathrm{ml} / \mathrm{min}$ while sleeping, $0.5 \mathrm{ml} / \mathrm{min}$ while spitting and up to $3 \mathrm{ml} / \mathrm{min}$ while chewing gum [11]. This flow rate may be influenced by several factors, including the individual's emotional state, pregnancy or menopausal-related hormonal changes, or by the use of drugs [9].

One common feature when collecting oral fluid samples is the so-called 'dry mouth syndrome'. This can be due not only to the anxiety provoked by the collection procedure, but also to a lack of proper hydration by the examinee [12]. Furthermore, the use of anti-adrenergic and anticholinergic drugs, or even of illicit drugs such as opiates, amphetamines and cannabis [9], may also contribute to this syndrome.

Different mechanisms for drug incorporation are thought to occur: passive diffusion through the membrane, active processes against a concentration gradient, filtration through pores in the membrane and pinocytosis $[3,13]$. Nevertheless, most drugs appear to be incorporated by a simple passive diffusion process that depends on their physicochemical properties (e.g., pKa and molecular weight), the degree of binding to plasma proteins and the $\mathrm{pH}$ of both blood and oral fluid [9,14].

Therefore, nonionized lipophilic drugs can easily cross the barrier between plasma and saliva, and their concentration in the latter is dependent on the nonprotein-bound plasma concentration. The low concentrations of diazepam and other benzodiazepines usually seen in this specimen represent a valid example of this dependence, since these compounds are highly protein bound $[15,16]$.

Drugs that are basic in nature, such as amphetamines, cocaine and opiates, generally have higher concentrations in oral fluid than in blood, whereas acidic drugs have much lower concentrations. The concentrations of $\Delta^{9}$-tetrahydrocannabinol (THC) in this specimen are more variable in oral fluid than in blood [4], possibly due to the deposition of THC in the oral cavity. Furthermore, current belief is that the majority of THC found in oral fluid originates from this depot of active THC [6], since little THC is secreted into saliva [17]. However, this effect is also seen for other drugs, such as nicotine after tobacco smoking and buprenorphine after sublingual administration [12].

The $\mathrm{pH}$ of oral fluid plays an important role in the case of weakly basic drugs, and can greatly affect their salivary concentrations. Indeed, those drugs whose $\mathrm{pKa}$ is close to the saliva's $\mathrm{pH}$ will have their degree of ionization dramatically altered with $\mathrm{pH}$ changes, and this will be reflected in their saliva-to-plasma ratio [10]. This influence of the salivary $\mathrm{pH}$ on the salivato-plasma ratio of several drugs is perhaps the reason why ratios determined experimentally differ from theoretical values calculated from the Henderson-Hasselbach equation [3,18] .

On the other hand, with an increase in the flow rate, the composition of the specimen will change, including its $\mathrm{pH}$, and therefore the circumstances of the collection can affect the production of oral fluid, which in turn will also change the drug content [8]. For this reason, the protocol for saliva collection can differ depending on the study (with or without stimulation) and may be highly important for the determination of saliva-to-plasma ratios [10].

However, care should be taken in the establishment of these ratios, since significant intraand inter-individual differences exist, which have been discussed elsewhere [19-25]. Nevertheless, these differences are not so large in the case of alcohol and antiepileptic drugs [22,25].

The research concerning oral fluid analysis in the case of alcohol consumption has been reviewed by Drummer [12], and the oral fluid-to-plasma concentration of this drug is similar to that predicted based on the water content of the two fluids, and has been used to assess alcohol exposure.

One important feature regarding oral fluid analysis is that, contrary to what happens when other biological specimens such as 
blood or urine are analyzed, the parent drug is the main compound detected, rather than its metabolites.

It should be noted, however, that there is the possibility of passive contamination in this type of analysis. This can occur mainly at two levels: by exposure to an environment where drugs are being consumed by others (e.g., exposure to cannabis smoke) [26] and by contamination from drugs taken orally, meaning that the detected drugs may not proceed from the bloodstream. Therefore, this possibility should be taken into account in the interpretation of the obtained results.

\section{Collection procedures \& devices}

There are two major advantages of oral fluid testing. First, as discussed above, drug concentrations in this specimen can be related to plasma free drug concentrations and, consequently, to the pharmacological effects of drugs. Second, saliva collection is made in a noninvasive and simple manner (under close observation, if necessary), without infringing on the examinee's privacy. This latter characteristic makes on-site specimen collection easy to perform, which is advantageous in the assessment of drug-impaired driving situations. Furthermore, the collection of this specimen is less liable to adulteration or substitution in comparison with urine sampling [27-29].

A variety of methods are available for oral fluid collection, with or without stimulation, and these include spiting, draining, suction and collection on various types of absorbent material. However, care should be taken since the concentration of the drugs can be affected by the collection procedure used.

Several techniques may be used to collect stimulated saliva, the simplest of which involves movements of the tongue, cheek or lip, without any external stimulus [30,31]. On the other hand, this stimulation can be made mechanically by chewing a variety of materials, such as paraffin wax, Parafilm ${ }^{\circledR}$, teflon, rubber bands or gum base [13,32]. Likewise, a lemon juice drop or citric acid can be placed in the mouth to provide a gustatory stimulus for saliva production $[11,30,32,33]$. Following this stimulation, saliva can then be spat, suctioned, absorbed or swabbed for collection [33].

This production stimulation may present several problems capable of compromising the accuracy of the test, however. For instance, there are some drugs and/or metabolites that can be absorbed by Parafilm, and paraffin contains compounds that may affect chromatographic analysis [34]. Furthermore, it is possible that the salivary composition is changed by the stimulation process, thereby potentially affecting drug concentrations in oral fluid $[13,35]$. In addition, citric acid changes saliva $\mathrm{pH}$, which may alter drug concentrations in this specimen, and has also been shown to alter immunoassay drug test results $[30,32]$. In fact, acidic stimulation has been shown to lower codeine [29,36], methamphetamine [37] and cocaine [38] concentrations in oral fluid.

Nonstimulated saliva can be collected by the draining method, which is performed by allowing saliva to drip from the mouth into a collection container [33], or can be easily obtained by spitting, providing a neat sample. However, this is relatively viscous and less easily pipetted than, for instance, urine, and its collection can pose potential occupational health and safety problems. In addition, and because it may also be contaminated with food, it may not provide a fluid of uniform concentration.

Therefore, the sample is typically collected using an absorbent $\mathrm{pad} /$ foam, which is subsequently squeezed or mixed into a diluent (usually buffer) to extract the oral fluid and provide a less-viscous and easier-to-analyze specimen. Some devices have a volume indicator, showing if sufficient oral fluid has already been collected [29,36].

However, the collected sample volume will often be less than $1 \mathrm{ml}$ and, therefore, sophisticated and sensitive detection techniques are mandatory to achieve the desired sensitivity, as will be further discussed.

The advantages and drawbacks of several collection devices have been extensively reviewed [39,40].

One of the problems that used to be associated with these collection devices was that the actual volume of sample was not accurately known. This has been overcome by the use of a volume adequacy indicator in the collection pad. This makes the collected volume well known, improving the accuracy of the measurements in this specimen. Indeed, for example, the Quantisal ${ }^{\mathrm{TM}}$ device's indicator turns blue when a sample volume of $1 \mathrm{ml}( \pm 10 \%)$ is collected [201].

Variable collection and recovery volumes between different devices may cause quantitative differences if it is assumed that:

- A consistent volume is collected

- A consistent volume is recovered from the device

- A consistent amount of drug is recovered from the device 
This latter issue is important, since it is well known that analyte recovery from the collection device is concentration dependent and this assumes particular relevance at low concentrations. For this reason, the evaluation of each device's performance in terms of analyte recovery should be targeted at a screening assay cut-off or a relevant physiological concentration.

Another approach to overcome the variability of collected volumes may be the weighing of the collection devices before and after sample collection [41].

A variety of devices for oral fluid testing are commercially available, such as OmniSal ${ }^{\circledR}$ (Cozart Biosciences Ltd, Abingdon, UK), Salivette ${ }^{\circledR}$ (Sarstedt AG, Rommelsdorf, Germany), Intercept ${ }^{\circledR}$ (OraSure Technologies, Bethlehem, PA, USA) and QuantisalTM (Immunalysis Corporation, Pomona, CA, USA). These devices usually consist of a sorbent material that becomes saturated in the mouth of the donor, and the oral fluid is recovered by centrifugation or by applying pressure $[42,43]$. The device is often placed in a container that contains a stabilizing buffer solution [44]. These buffer solutions are not the same for all the devices that use this type of approach, and this is why these devices show differences in their performance, for example concerning drug recovery. The acceptability of sample collection devices is determined both by the speed of collection and ease of handling, and the referred devices all have their advantages and drawbacks. In addition, attention should be paid to the devices' performance, as some collectors have been shown to absorb $\operatorname{drug}(\mathrm{s})$ irreversibly, meaning that the drugs are not able to leach out into the postcollection buffer, impairing the accuracy of quantitative analysis. Several studies have been made on this issue, and it appears that drugs are not affected to the same extent. Some studies have even obtained contradictory results.

Indeed, in one study, a recovery of codeine from the Salivette device of more than $80 \%$ was reported [36,45]; while, in another study, lower recoveries (39-42\%) were found [29,39]. On the other hand, only approximately $38 \%$ of THC is recovered from the Intercept device, whereas recoveries of 3,4-methylenedioxymethamphetamine (MDMA), cocaine, morphine, codeine, diazepam and alprazolam from the same device are much higher [39]. Moreover, the Cozart ${ }^{\circledR}$ collector shows good recovery for THC $[36,46,47]$ and methamphetamine $[37,48]$.
Significant differences in drug recoveries from the sampling material are reported in the literature, and these will also lead to variations in the measured concentrations in oral fluid.

Several solutions are proposed to overcome this problem. For instance, a modification of the sampling procedure for the Intercept collector, which consisted of the addition of methanol to the elution buffer, resulted in complete recovery of THC over a large concentration range [41]. Other studies were conducted on the recovery of other drugs from the same device [49,50], and significant losses for 7-aminoclonazepam and lysergic acid diethylamide (LSD) were found. Another study, by Quintela et al. [48], evaluated the in vitro performance of the Quantisal device for amphetamine, methamphetamine, morphine, codeine, cocaine, benzoylecgonine (BE), methadone, oxazepam and THC. In general, recoveries were higher than $90 \%$, but lower for BE $(82 \%)$.

For THC, however, high recovery was obtained (81.3-91.4\%). Other previous studies, using Salivette, showed that significant amounts of the drugs remained entrapped on the device [51-53].

Another important feature that should be taken into account in oral fluid analysis is drug stability or, more accurately, drug instability in the matrix, which can affect the utility of the collection process [40]. The inherent chemical instability of drugs may be exacerbated in oral fluid by the collection device and/or buffer. This issue is of utmost importance in oral fluid analysis, together with analyte recovery from the collection device, because drug concentrations are generally low in this specimen and, therefore, the detectability of the drug may be limited [8]. Stability of several analytes, such as THC, morphine, 6-acetylmorphine (MAM), BE and designer amphetamines, was evaluated in oral fluid samples after collection and was extensively discussed [29,48,54-57].

The stability of analytes can be affected by a number of conditions, including the use of preservatives in the case of flunitrazepam [58] and storage temperature and duration in the case of MAM [59] or THC [29].

In conclusion, no type of collection device is clearly superior based on design or ease of use. On the other hand, the recovery studies conducted on some devices do suggest that drug desorption may limit the usability of some collection materials. Therefore, more information is required for all drugs likely to be measured in oral fluid, and for each collection device. 


\section{Applicability of oral fluid analysis}

Oral fluid can be used to assess an individual's exposure to virtually every class of compounds, but drugs of abuse are by far the most detected substances. This is mainly due to the deleterious consequences of these substances' misuse, both in workplace medicine and motor vehicle driving. For this reason, scientific literature is prolific in analytical techniques aimed at detecting and quantitating a variety of classes of abused drugs, namely opiates [52,60-65], cannabinoids [54,66-71], amphetamines [21,55,72-77], cocaine [78,79] and benzodiazepines [58,80-87]. Other substances such as ketamine, $\boldsymbol{\gamma}$-hydroxybutyrate (GHB) [88,89], antibiotics [90], analgesics [91,92], antitussives [93], cyanides and other tobacco compounds [94-96], and sildenafil [97], have also been analyzed. Oral fluid has additional relevance in the case of opiate testing, since high amounts of 6-monoacetylmorphine can be detected in oral fluid in the case of heroin consumption, as well as detectable amounts of heroin itself, and therefore heroin abuse can be easily detected [12].

Oral fluid presents a wide field of analytical applications that take advantage of the aforementioned advantages [2] concerning, for example, therapeutic drug monitoring $[1,25,45,80,98,99]$, pharmacokinetic studies $[4,5,19,37,100]$, workplace medicine $[27,101,102]$ or even detection of illicit drugs in driving situations [47,103-112].

The application of oral fluid analysis to assess drug prevalence is definitely desired, and a positive correlation to impairment has already been shown [106,113]. However, it should be pointed out that, for most substances, a measured oral fluid concentration cannot be used to predict the corresponding plasma concentration, due to the intra- and inter-individual differences discussed earlier.

Nevertheless, the assessment of drug-impaired driving is one of the most impacting applications of oral fluid testing, which has contributed to the development of several collection materials for laboratorial analysis and collection devices designated for on-site applications.

\section{Analytical technologies}

Due to developments in technology, it is possible to detect and quantitate drugs in biological specimens at levels that were unreachable a few years ago. As discussed earlier, one of the main disadvantages of oral fluid is the fact that one must be able to detect very small amounts of drugs, due both to their low concentration in this specimen and to the fact that usually there is little sample available for analysis (often less than $1 \mathrm{ml}$ ). This latter drawback may be manageable by the use of multianalyte methods, providing the optimization of sample volume and eventually of confirmation analysis, if necessary. Therefore, the development of this type of method is highly desirable for oral fluid drug testing. For instance, Gunnar et al. have published a method by gas chromatography (GS)-mass spectroscopy (MS) that is capable of determining 30 derivatized drugs in $250 \mu \mathrm{l}$ of oral fluid [49]. A few LC-MS/ MS multianalyte methods have also been published, allowing the simultaneous determination of several abused drugs [50,114,115], benzodiazepines and hypnotics $[50,115]$. A method for the simultaneous determination of 49 substances, including some antipsychotics and antidepressants, has also been published [116]. Therefore, sensitive and selective techniques are mandatory to achieve the desired low levels. The main analytical techniques usable for drug detection, including their advantages and drawbacks and the main parameters that can affect the analysis, will now be discussed, in light of existing literature on the matter.

\section{- On-site collection devices}

The increased use of illegal drugs gave rise to the need for quick and reliable methods, which have been developed and improved since the 1990s [103], for the fast screening of drugged drivers.

Portable devices have been developed for drug detection in several biological fluids, namely urine, oral fluid and sweat. The performance of various urine on-site screening tests has been evaluated $[117,118]$. However, as stated previously, oral fluid concentrations of drugs can be related to their plasma concentrations and, therefore, to the pharmacological state of the individual $[119,120]$, while drug detection in urine does not necessarily mean that the individual was influenced at that specific time [121]. Therefore, and due to the ease of its collection, oral fluid seems to be a better sample for this purpose compared with urine.

One advantage of these portable devices is that they allow the initial testing for drugs to be easily carried out in the field. A preliminary drug test result is usually provided within a few minutes, without the need for sophisticated and/ or expensive laboratory equipment. Indeed, easyto-use instruments are available that provide an electronic readout (e.g., Dräger DrugTest ${ }^{\circledR}$ and Orasure Uplink ${ }^{\circledR}$, Cozart Rapiscan ${ }^{\circledR}$ and Drugread $^{\circledR}$ hand photometer), while others
DRUGS OF ABUSE

Most publications concerning oral fluid analysis aim at detecting these substances 
require visual identification (e.g., DrugWipe ${ }^{\circledR}$, iScreen OFD ${ }^{\mathrm{TM}}$, OralScreen ${ }^{\circledR}$, Oratect ${ }^{\circledR}$ and SalivaScreen ${ }^{\mathrm{TM}}$ ) [2]. On-site collection kits may also provide an indirect aid to traffic control, since the tested individual is more likely to admit drug use after a positive test result. On the other hand, individuals under the influence of drugs may be deterred from driving, since people are starting to become aware that traffic control police are able to perform screening tests for drug use [103].

However, the assessment of these devices' performance is not objective, because, for most, the specifications are not consistent [2] and details concerning the detectability conditions are often missing. On the other hand, the ease of use of the devices should also be evaluated, taking into consideration the opinion of traffic regulation officers, since they are the ones who will be using them in the field.

The possibility of supervision of the sampling process is especially important in terms of law enforcement, since sample adulteration is avoided and the possibility of substitution or contamination appears to be minimal. For these reasons, the significance of oral fluid as a primary matrix in roadside testing can hardly be questioned. Indeed, oral fluid testing has revealed its usefulness in detecting drugs of abuse in various studies using several devices [46,106,122-130], and it can be seen as a good substitute for whole-blood samples [128], unless a quantitative analysis of blood levels is desired.

The advantages of on-site testing are rapid turnaround times, reduced costs and the fact that the test can be carried out virtually anywhere [129]. However, this type of technology presents some problems relating to THC detection, since the removal of the drug from the collection pad is difficult $[67,130]$.

The scourge of driving under the influence of drugs or alcohol is responsible for thousands of accidents every year, and up to $25 \%$ of them involve drivers who tested positive for drugs [131]. For instance, in a roadside study by Samyn et al., blood analysis of drivers suspected of impairment revealed the presence of MDMA in 35\% of cases; in addition, amphetamine, cocaine and cannabis were detected in many of these [104].

The deleterious consequences of drugimpaired driving on road safety led the European Commission to promote scientific studies based on oral fluid analysis.

The first of these studies was the Roadside Testing Assessment (ROSITA), aimed at assessing the value of on-site tests at the roadside, and also to give recommendations for the use of roadside testing equipment in European countries. Police officers from 16 countries were surveyed, and saliva was shown to be the preferred matrix for drug testing. The reasons for such a choice are quite obvious, namely its ready availability, low invasiveness and good correlation with impairment. Test configuration was also evaluated in this survey, and the ideal would be a single-use multianalyte test able to provide a clear and unambiguous test result within a 5-min interval [103,202]. A collaborative study between the USA and the European Union (ROSITA-2) has been conducted both to assess illegal drug use among motor vehicle operators and to evaluate the effectiveness of on-site oral fluid drug-detection technologies. Within the scope of this study, which was completed in 2005, Crouch et al. have tested the laboratorial performance of ten different devices, namely concerning their ability to meet the manufacturers' claimed cut-off concentrations for several drug classes, including amphetamines, cocaine and metabolites, opiates and cannabinoids [132]. Two devices were also evaluated for benzodiazepines. The devices' results were compared with laboratory-based immunoassay and MS results, both in terms of sensitivity and specificity.

Another study is ongoing in Europe, the Integrated Project Driving under the Influence of Drugs, Alcohol and Medicines (DRUID), which involves more than 20 European countries. The objective of this study is to gain new insights to the real degree of impairment caused by psychoactive drugs and their actual impact on road safety, giving scientific support to the EU transport policy to establish guidelines and measures to combat impaired driving [203].

A study has been conducted in the US (Pilot Test of New Roadside Survey Methodology for Impaired Driving), aimed at developing and testing new procedures for the assessment of impaired driving. In this study, oral fluid samples of over 600 randomly selected drivers were collected and analyzed, and blood was also collected in approximately half of those subjects. Several drug classes were included in this study, including both abused and prescription drugs [204].

\section{Immunoassays}

In recent years, extraordinary advances in analytical techniques have enabled the detection of drugs and metabolites in alternative specimens. The strategy for drug testing in biological fluids (e.g., urine, blood and oral fluid) usually 
begins with screening procedures, which should be able to detect or exclude a drug class and elude false-negative results [3]. This is extremely useful, especially for those laboratories that are required to analyze a large number of samples routinely, saving time and money that would be wasted in more expensive confirmatory methods (usually MS-based techniques), while most of the samples would be negative.

Four interpretations are possible following a drug test:

- True-positive, when the test correctly detects a drug in the analyzed specimen

- False-positive, when the test incorrectly detects the presence of a drug where no drug is present

- True-negative, if the test correctly confirms the absence of a drug

- False-negative, when the test fails to detect a drug that is actually present in the sample

A test's sensitivity is determined by its ability to detect the presence of a drug at or above a cut-off level [133].

For obvious reasons, to choose this cut-off level one must optimize the number of truepositive and true-negative samples, and the number of false-positives and false-negatives should be kept to a minimum. Indeed, if the cut-off is set too low, the number of falsepositive samples will be too high and there will be an unnecessary high number of confirmation analyses, as stated previously. On the other hand, a cut-off value that is too high will lead to a large number of false-negative samples, impairing the test's usefulness in its applications, namely in the clinical and forensic fields [44]. However, this is not an easy task, since these tests are designed for maximum sensitivity, in order to minimize the possibility of a false-negative sample, which increases the probability of obtaining a false-positive result.

Another common characteristic of immunoassays is their specificity or, more accurately, their lack of specificity. This means that these tests are, in general, not able to discriminate between different drugs or metabolites from the same class. On the other hand, there is also the possibility of a false-positive result deriving from the consumption of some overthe-counter medications, which are known to interfere with amphetamine screenings, originating a positive result. Perhaps the term 'presumptive positive' would be more accurate to define this situation, since that sample would be positive, although not for drugs in the confirmation profile. This phenomenon is known as cross-reactivity, and it also occurs when the test cannot distinguish between chemically similar substances [81,133].

Despite these drawbacks, immunoassay techniques are the most commonly used methods for the screening of illicit drugs in biological specimens, including urine, blood and other matrices such as oral fluid and hair. This is due to the advantages that they present over other techniques, namely that the sample volume needed to perform the test is small (usually approximately $25 \mu \mathrm{l}$ ), which is extremely important in oral fluid analysis, since the amount of sample available is usually limited, and there is no need for sample pretreatment [44].

A few studies have been published on the use of immunoassays for drug screening in oral fluid, and these concerned the detection of opiates $[40,54,60,134]$, including methadone and its metabolite 2-ethylidene- 1,5-dimethyl3,3-diphenylpyrrolidine (EDDP) [135], cocaine and metabolites [57,136-139], cannabinoids [40] and amphetamines $[40,140,141]$. Benzodiazepines were also screened using this specimen $[40,81]$ and, more recently, dextromethorphan [95] was also studied.

Special attention should be paid to the analytical challenge that the screening of highly potent benzodiazepines, such as flunitrazepam, represents in oral fluid analysis. Indeed, these compounds are usually present in the low nanogram range $[58,86]$ and, therefore, often remain undetected by traditional enzymatic assays. This lack of sensitivity may be overcome by the use of specific immunoassays for these substances or their metabolites. Indeed, studies have been performed on this type of assay [142], although their use in oral fluid analysis is not documented.

Immunoassay-based techniques represent highly sensitive and cost-effective technology; however, their lack of specificity makes the confirmation of presumptive-positive samples mandatory. This confirmation analysis is usually performed by highly specific MS-based methods, which are designed to identify unequivocally the present $\operatorname{drug}(\mathrm{s})$ and elude false-positive results.

The reader is referred to the review by Townsend et al. for a more comprehensive insight on immunoassay techniques, including biosensor technology [143]. 
- Gas chromatography-mass spectrometry Both qualitative and quantitative toxicological analyses are required to be reliable, and this applies to all fields of analytical toxicology, including clinical and forensics. The hyphenation of chromatographic techniques to mass spectrometers has brought a significant improvement in drug testing in biological specimens. This is of particular importance in the fields of clinical and forensic toxicology, for which the needed specificity and sensitivity could be met [144].

Gas chromatography-mass spectrometry was the most utilized technique for the confirmation of a number of organic compounds back in the 1990 s, mainly due to the availability of spectral libraries for drugs and metabolites [145].

In addition, GC-MS is a very reproducible technique, and consistent mass spectra can be obtained in different laboratories, providing that the ionization conditions are the same (usually electron ionization at $70 \mathrm{eV}$ ). This is the reason why it is still the gold standard in mass detection specificity [146].

Gas chromatography-mass spectrometry is currently available in most laboratories, and this is still the main technique for confirmation and quantitation of drugs and their metabolites in biological specimens, including the so-called 'alternative' specimens such as oral fluid, hair and sweat.

Analysis by GC-MS generally requires the extraction of the analytes from the matrix and, in most cases, their chemical derivatization in order to improve peak shape and/or allow chromatographic analysis. Typical limits of quantitation are in the range of approximately $1-10 \mathrm{ng} / \mathrm{ml}$, and the ability to achieve them obviously depends on the sample volume. This presents a limitation in terms of oral fluid, not only because of the low amounts at which drugs are present in this specimen, but also due to sample availability for analysis. For example, typical concentrations of 11-nor- $\Delta 9$-tetrahydrocannabinol-9-carboxylic acid in oral fluid are in the low picograms per milliliter range [66]. Analysis of these low amounts of drugs in biological matrices are, in general, impaired by the presence of co-extracted endogenous compounds, which usually lead to an increase in the background noise, decreasing the analyte's signal-to-noise ratio $(\mathrm{S} / \mathrm{N})$. Therefore, and to perform a valid quantification, the $\mathrm{S} / \mathrm{N}$ must be increased, which can be performed using $2 \mathrm{D}$ chromatography. This method is able to augment $\mathrm{S} / \mathrm{N}$ by the selective transfer of a small segment of GC eluent that contains the analytes of interest to a second column coupled to a mass spectrometer, reducing or eliminating the interference of endogenous substances $[67,147]$.

The S/N may also be increased using MS/ MS, which allow LODs of approximately $0.01 \mathrm{ng} / \mathrm{ml}$ [66]. This type of technology was developed for the measurement of low-concentration analytes in biological samples, including blood and urine. However, it is also extremely useful in those situations where sample amount is critical, as frequently occurs when abused drugs and their metabolites are analyzed in alternative matrices. Of particular interest is its application to drugs that represent a more challenging analytical assay (e.g., cannabinoids), therefore requiring a MS/MS approach to achieve the required limits of detection.

Another type of GC-MS/MS technology applicable in oral fluid analysis is the ion-trap MS. These mass spectrometers create a magnetic field that holds the formed ions until they are sequentially released to the detector. Many of the advantages of an ion-trap derive from being able to monitor ions on demand, which means that they can be accumulated in the trap to improve sensitivity.

When the number of analytes is too big, an approach is to use fast GC methods, which allows a reduction in the time of analysis, maintaining acceptable resolution. Fast GC was developed following modifications on the quadrupole mass spectrometers, including reduced column bore size and more efficient capillary columns, rapid heating-rate ovens and high-pressure carrier gas control [147]. Applications include the ability to analyze 30 different drugs in oral fluid [49].

Several papers have been published on the use of GC-MS/MS for oral fluid analysis, including the detection and quantitation of several drug classes in this specimen. For a better understanding, most of the papers published over the last decade are summarized in TABLE I [148-156].

\section{- Liquid chromatography- mass spectrometry}

Recent years have seen the development of powerful technologies that have provided forensic scientists with new analytical capabilities that were unthinkable only a few years ago [157]. The most spectacular analytical improvement was the advent of LC-MS, for which there has been an explosion in the range of new products available for solving many analytical problems, 


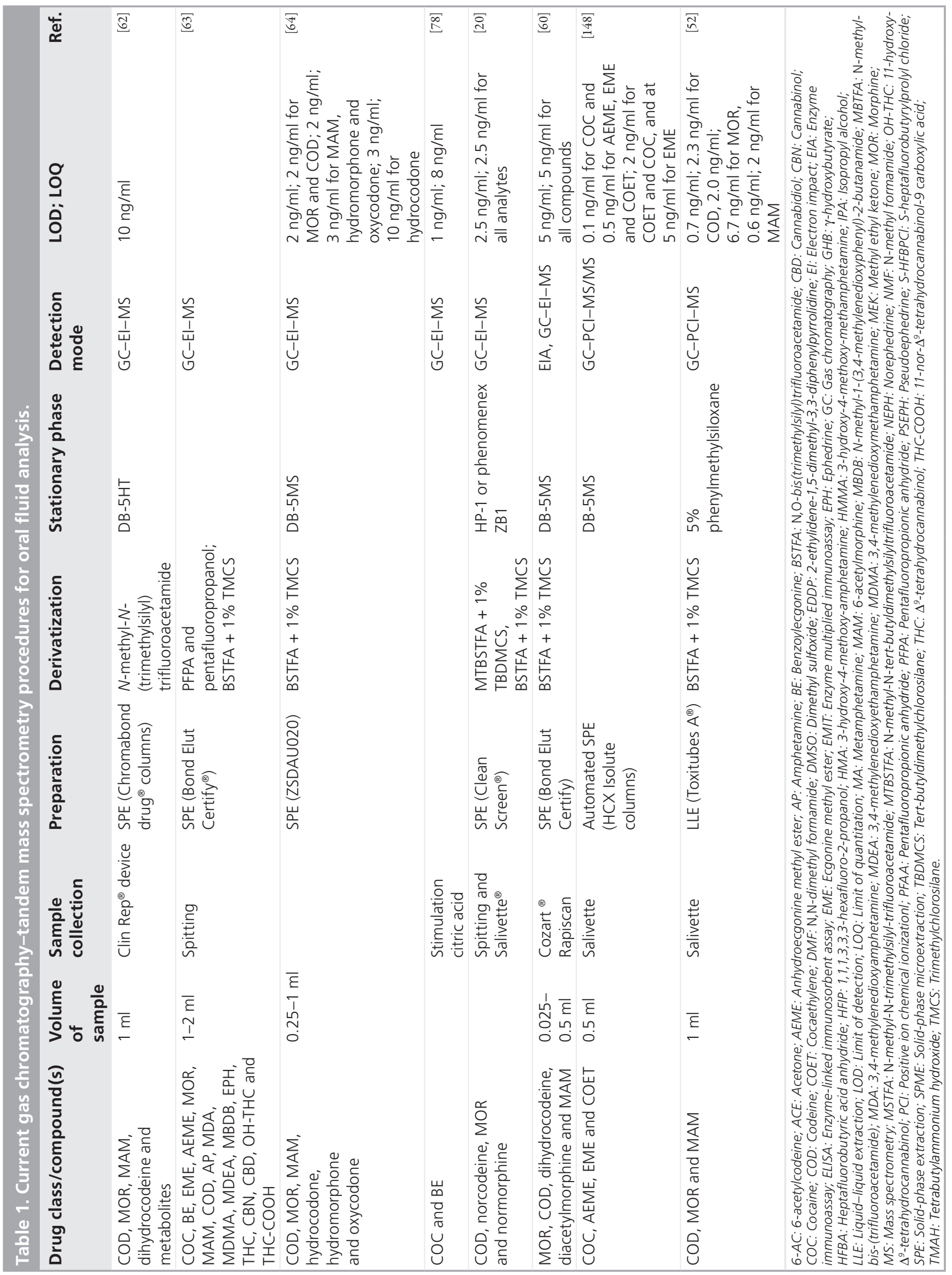




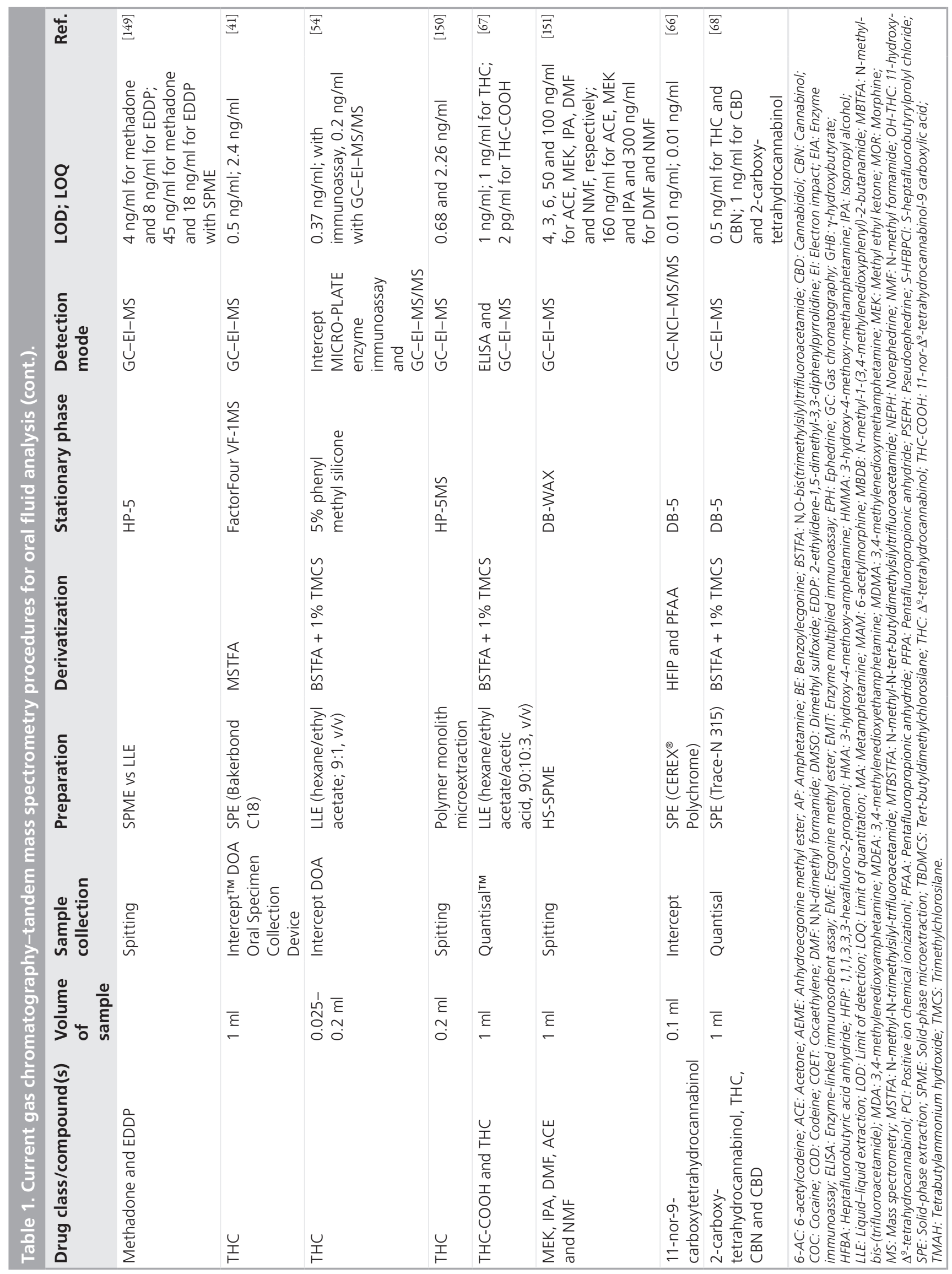




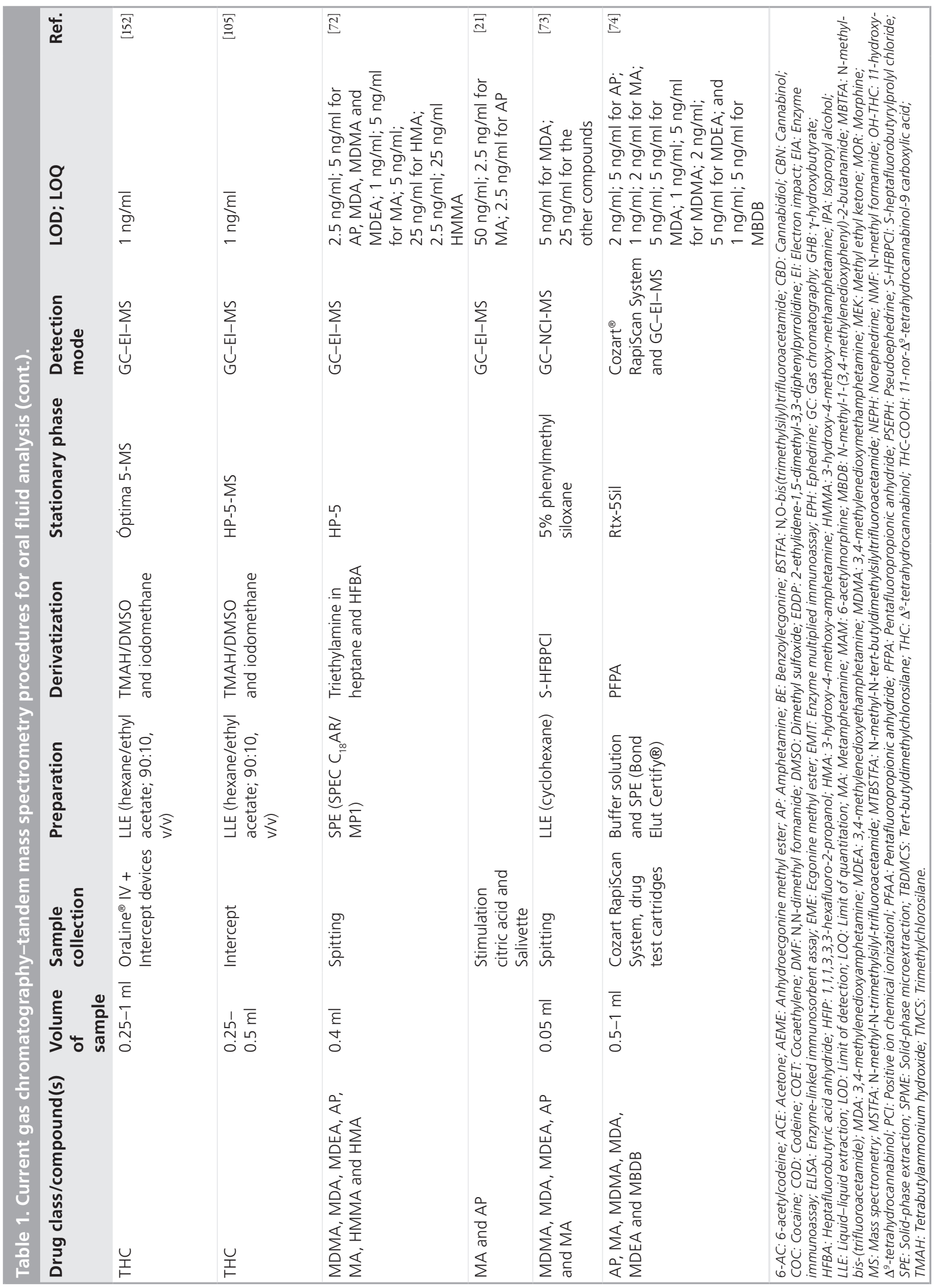




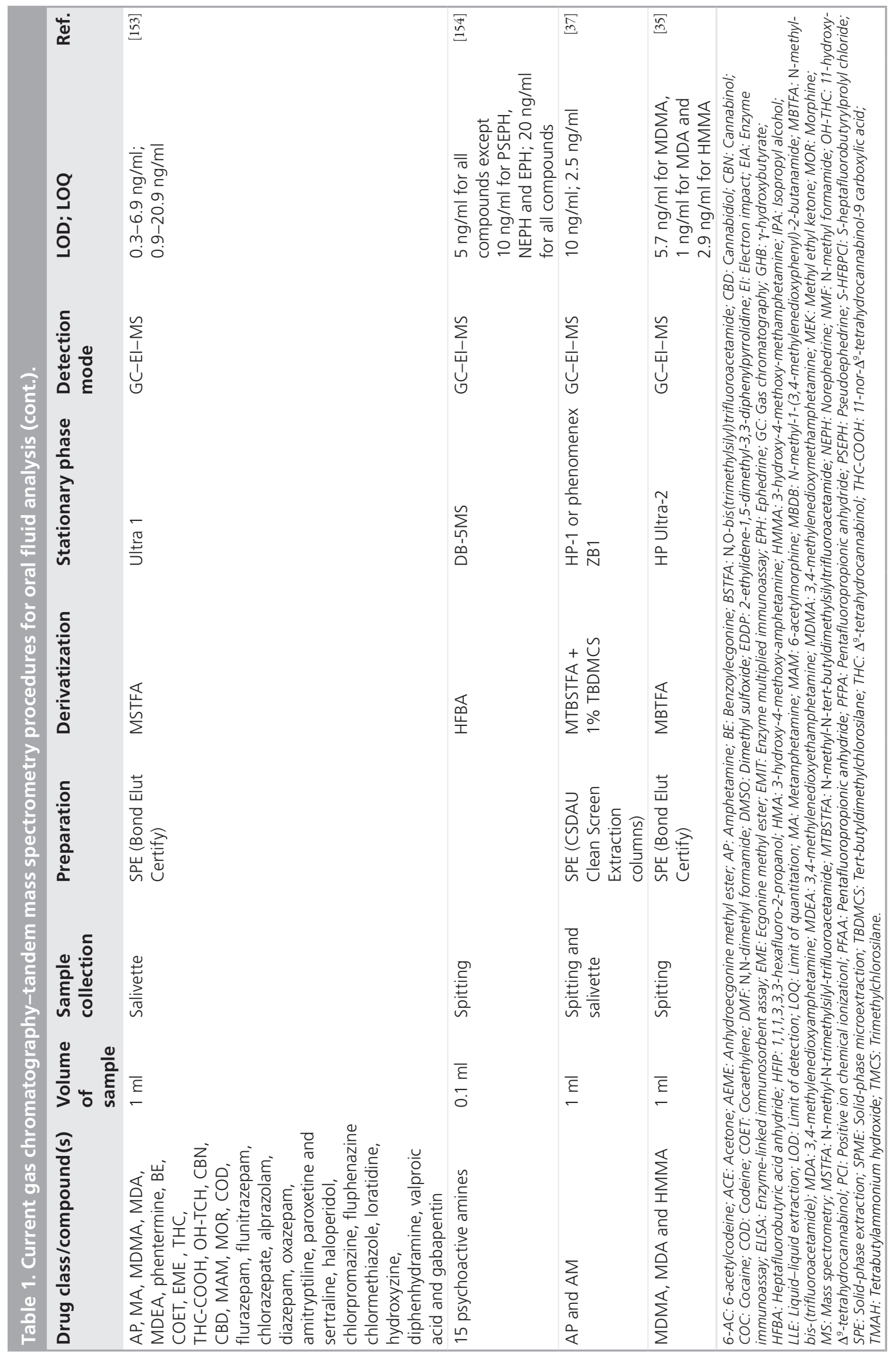




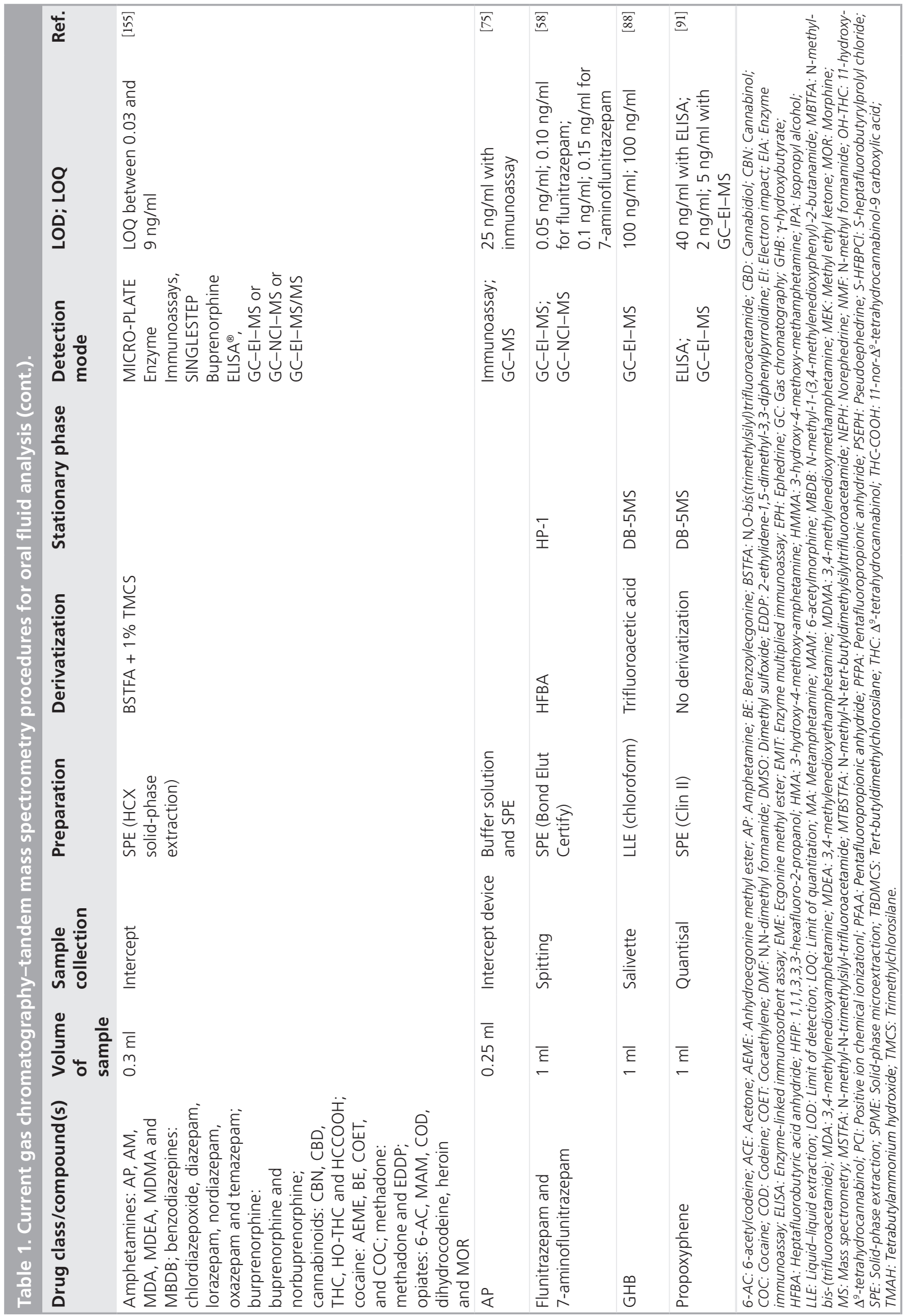




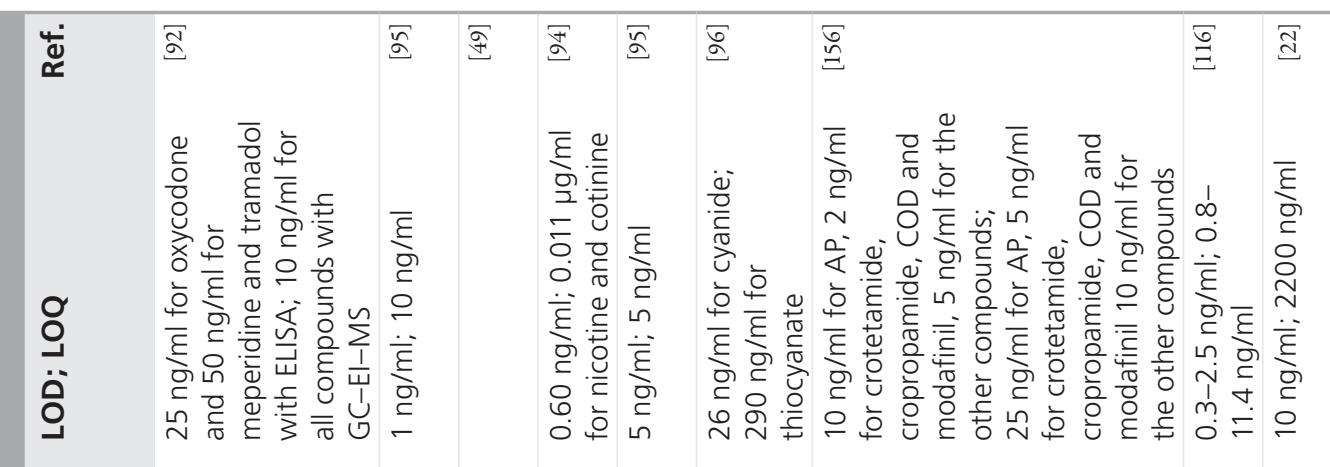

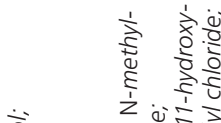

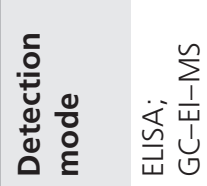

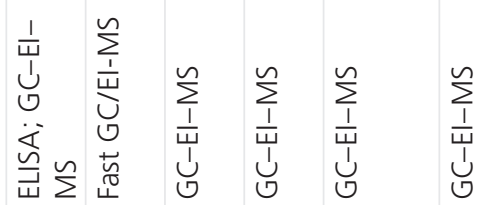

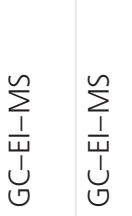

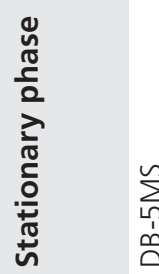

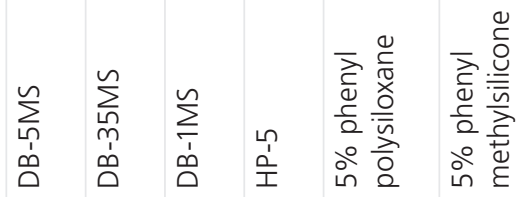

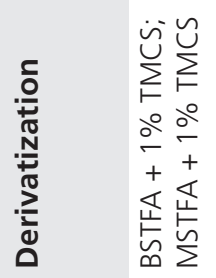

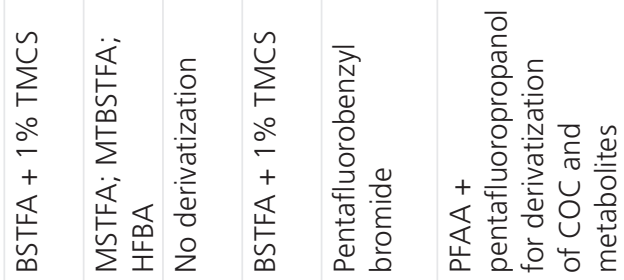

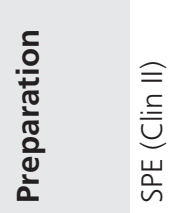

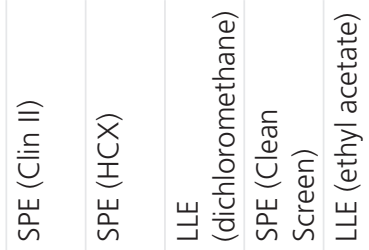
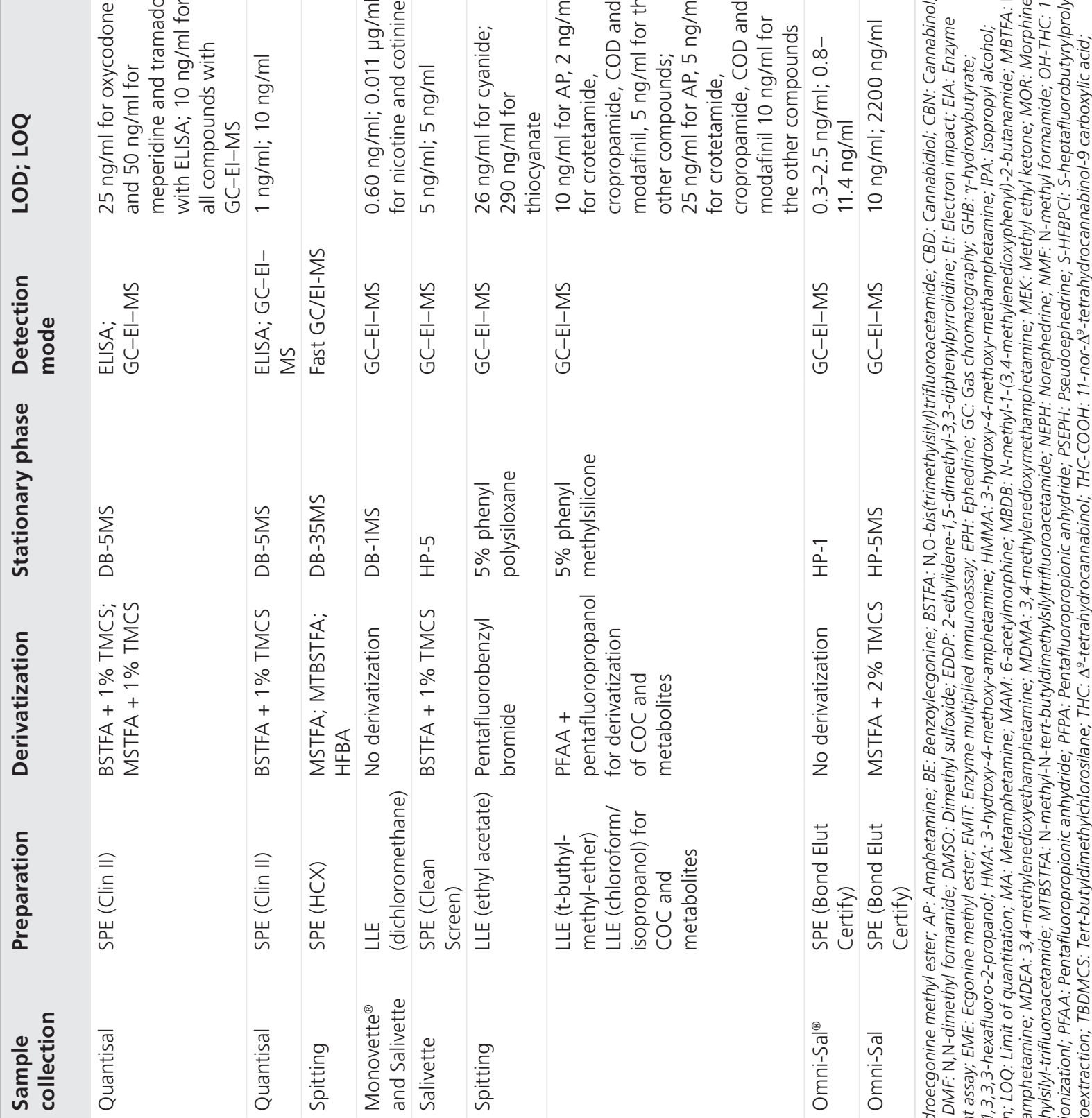

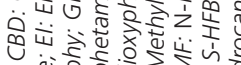

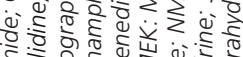

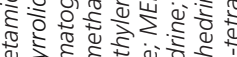

0
0
0
0
0

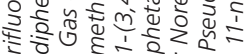

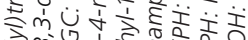

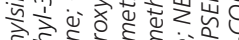

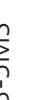

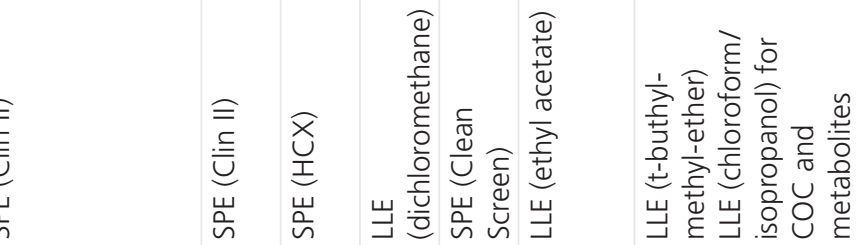

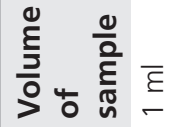

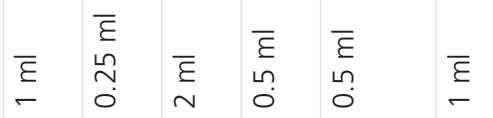
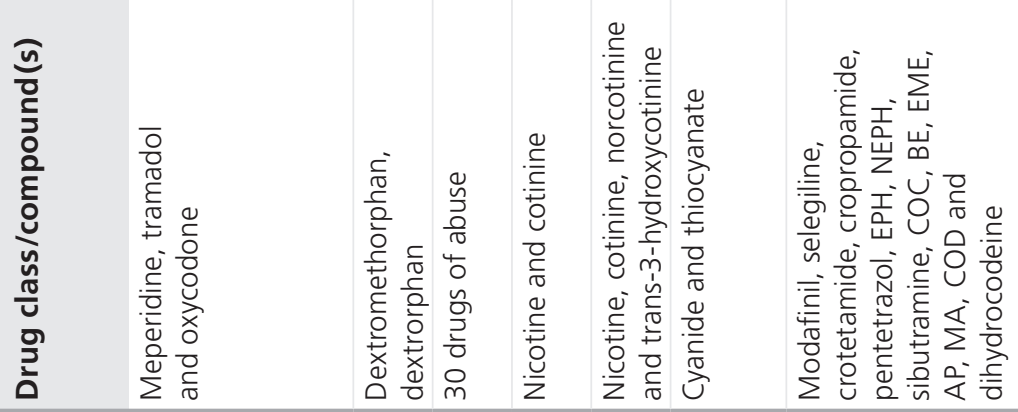

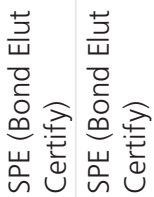

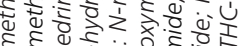

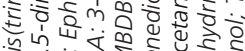

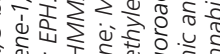

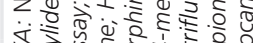

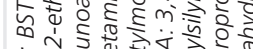

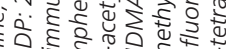
वे की

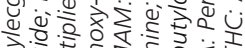

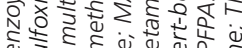
$\infty$ जे


हो)

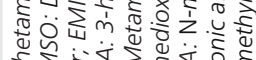





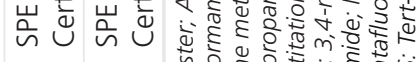

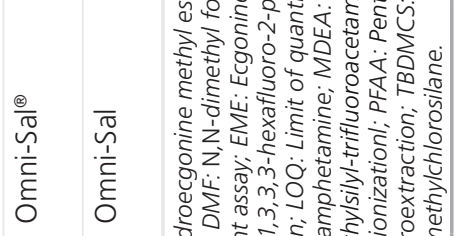


especially for those applications aimed at analyzing nonvolatile, labile and/or high-molecular-weight compounds. In the last 10 years, an important step was made toward LC-MS-based scientific investigation. Electrospray ionization (ESI) and atmospheric pressure chemical ionization (APCI) have become the most widespread ionization techniques [158].

However, assessing which of these ionization techniques is more suitable for developing a new procedure must be made on a case-by-case basis. For example, APCI is more appropriate for unionized analytes, and the sensitivity depends on the analyte structure and apparatus [144]. On the other hand, ESI interfaces permit MS analyses of molecules in the molecular weight range of drugs of abuse (50-600 Da) or larger molecules, including proteins as large as $232 \mathrm{kDa}$ [147]; this is the most used ionization technique.

Related to LC-MS, tandem mass spectrometry (LC-MS/MS) offers superior sensitivity and specificity, especially if compared with the use of a single quadrupole. These instruments, when operated in the multiple reaction monitoring mode (MRM), allow the detection of extremely low levels of analytes in complex biological samples, reducing sample pretreatment and analysis time.

One limitation of LC-MS/MS, mainly in ESI mode, is its susceptibility to matrix effects, causing unwanted ion suppression or enhancement [159-162]. For example, Dams et al. found that ESI and APCI showed matrix effects, with ESI being much more susceptible than APCI [161]. Indeed, the common and early perception that utilization of LC-MS/MS practically guarantees selectivity is being challenged by a number of reported examples of lack of selectivity due to ion suppression or enhancement phenomena caused by the sample matrix and interferences from metabolites, as well as 'cross-talk' effects.

These effects are capable of affecting ion ratios in the mass spectrum, potentially impairing the assay's accuracy. Several strategies can be used to evaluate and overcome this problem, and these have been reviewed by Matuszewski et al. [163].

Ion-suppression effects may occur to a greater extent with increased solvent amount in the chamber. This problem can be addressed via the reduction of the amount of mobile phase exiting the column by means of nano-LC systems, which will be further discussed below. Another possible approach is to reduce matrix constituents by reducing sample volume or adjusting mobile-phase composition in order to reduce coelution of matrix components with target analytes. In addition, matrix-matched calibrators and deuterated internal standards should also be used.

Another problem that LC-MS and LC-MS/ MS methods may present is the formation of adducts by combination with $\mathrm{Na}^{+}, \mathrm{K}^{+}$or $\mathrm{NH}^{+}$ introduced by the solvent in the chamber. These adducts produce ions of mass-to-charge ratios higher than expected by factors of 23,40 or $18 \mathrm{Da}$. In addition, these adducts do contain multiple salt ions and are capable of forming bridges between ions of differing masses, which will complicate mass spectra interpretation $[164,165]$.

Unlike GC-MS, the development of searchable libraries for LC-MS and LC-MS/MS is still a problem, since fragmentation and spectra differ between instruments. However, despite interinstrument reproducibility, these spectra do have many similar features $[166,167]$.

Recently, two research groups have been creating homemade libraries, allowing the identification of therapeutic agents and drugs of abuse, by means of the collision-induced-dissociation (CID) approach [168-172]. Briefly, the ions are accelerated and a high number of collisions are produced with gaseous solvent molecules, leading to analyte dissociation. These fragments allow the confirmation of the compound's identity, and it is possible to design a library for each instrument.

Liquid chromatography-MS presents a number of advantages over GC-MS, especially for the quantitation of more polar, termolabile or low-dosed drugs [144], avoiding the complicated and laborious derivatization procedures usually necessary in GC analysis [173,174]. Furthermore, these needed derivatization steps may differ for different compound classes according to their chemical structure. Indeed, for example, amphetamines are often derivatized by acetylation, while opiates originate better signals using silylating agents. This will pose several difficulties in the development of multi-analyte methods, which is desirable in oral fluid analysis, as stated earlier.

As discussed previously, nano-LC systems represent a valid approach to overcome ion-suppression phenomena, since the amount of solvent present in the chamber is reduced, achieving lower limits of detection. In fact, Tomkins et al. reported a chip-based nanoelectrospray MS/MS method that could detect $0.49 \mathrm{ng}$ of cotinine (metabolite of nicotine) in $1 \mathrm{ml}$ of oral fluid [175]. The amount of specimen extract on the chip was $10 \mu l$, providing a detection limit of $4.9 \mathrm{pg}$ on the column. Accuracy and precision results were not 


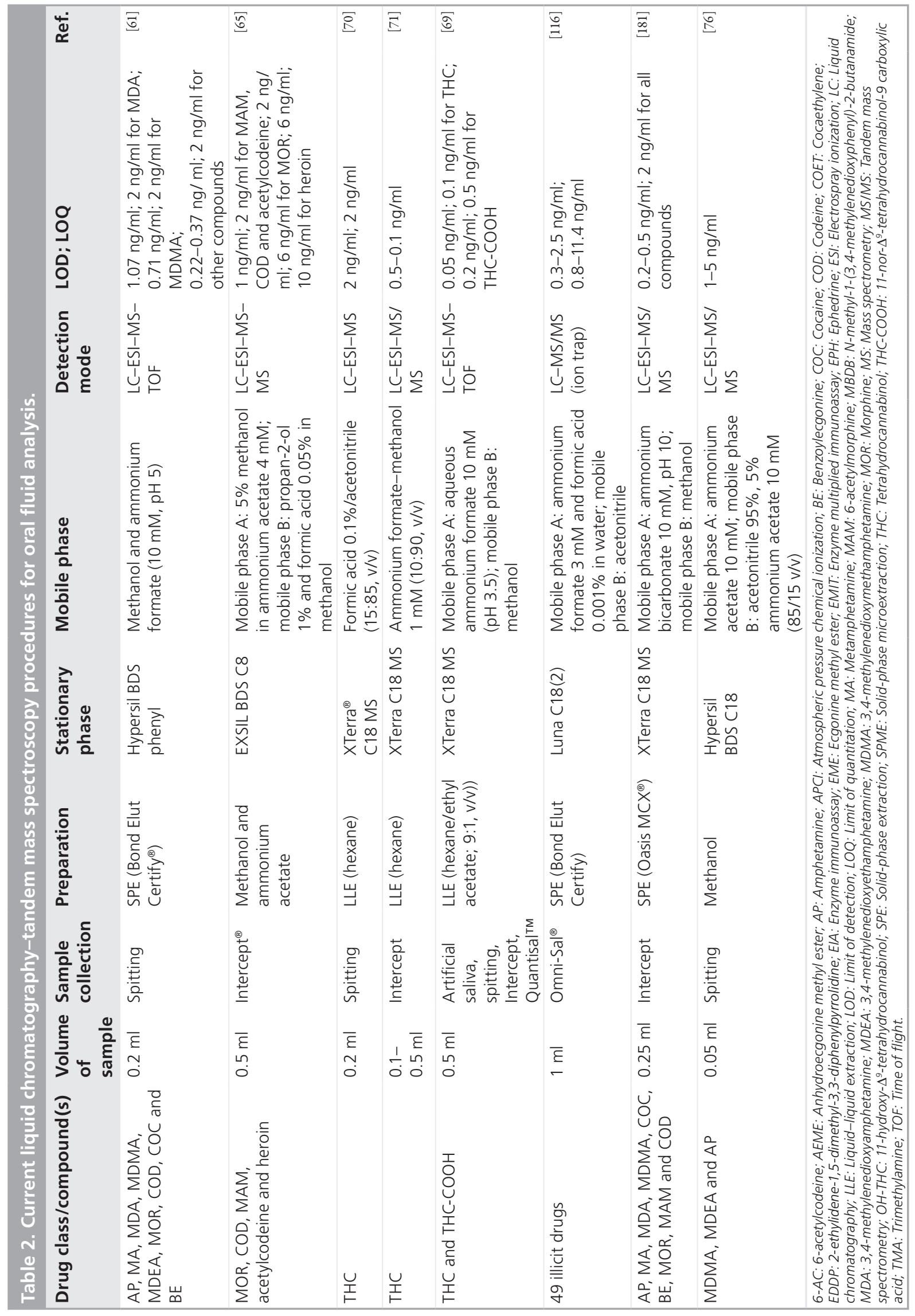









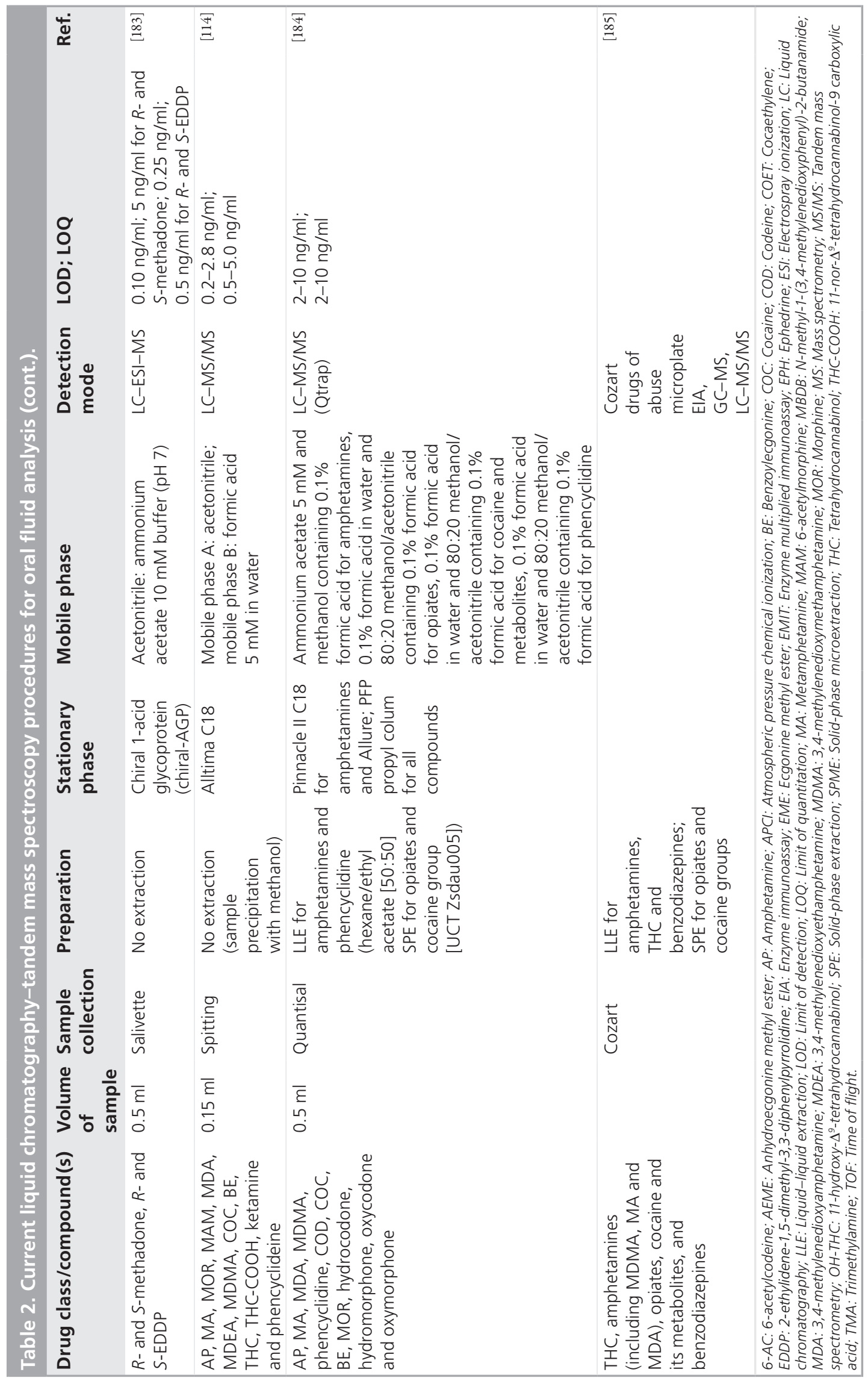




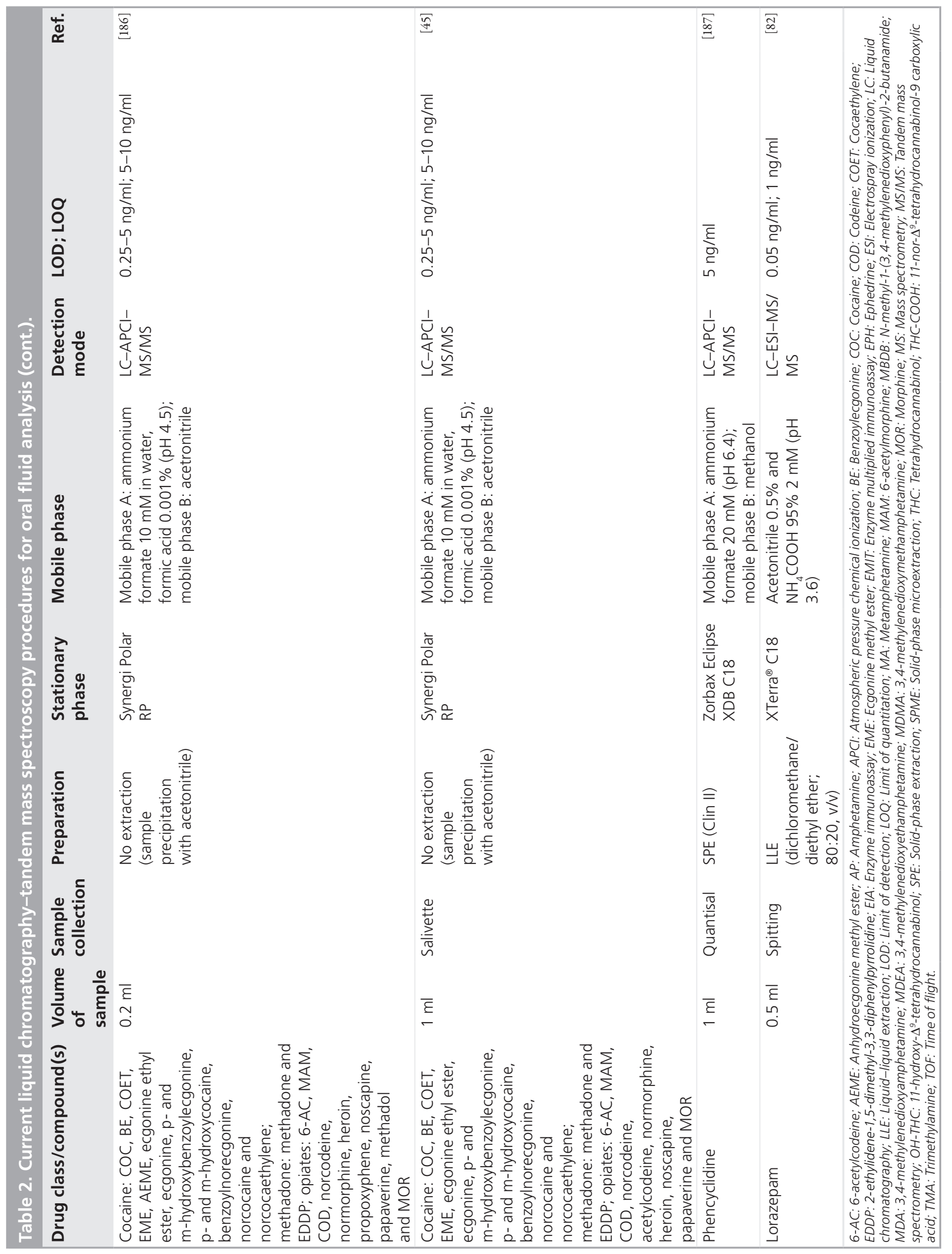




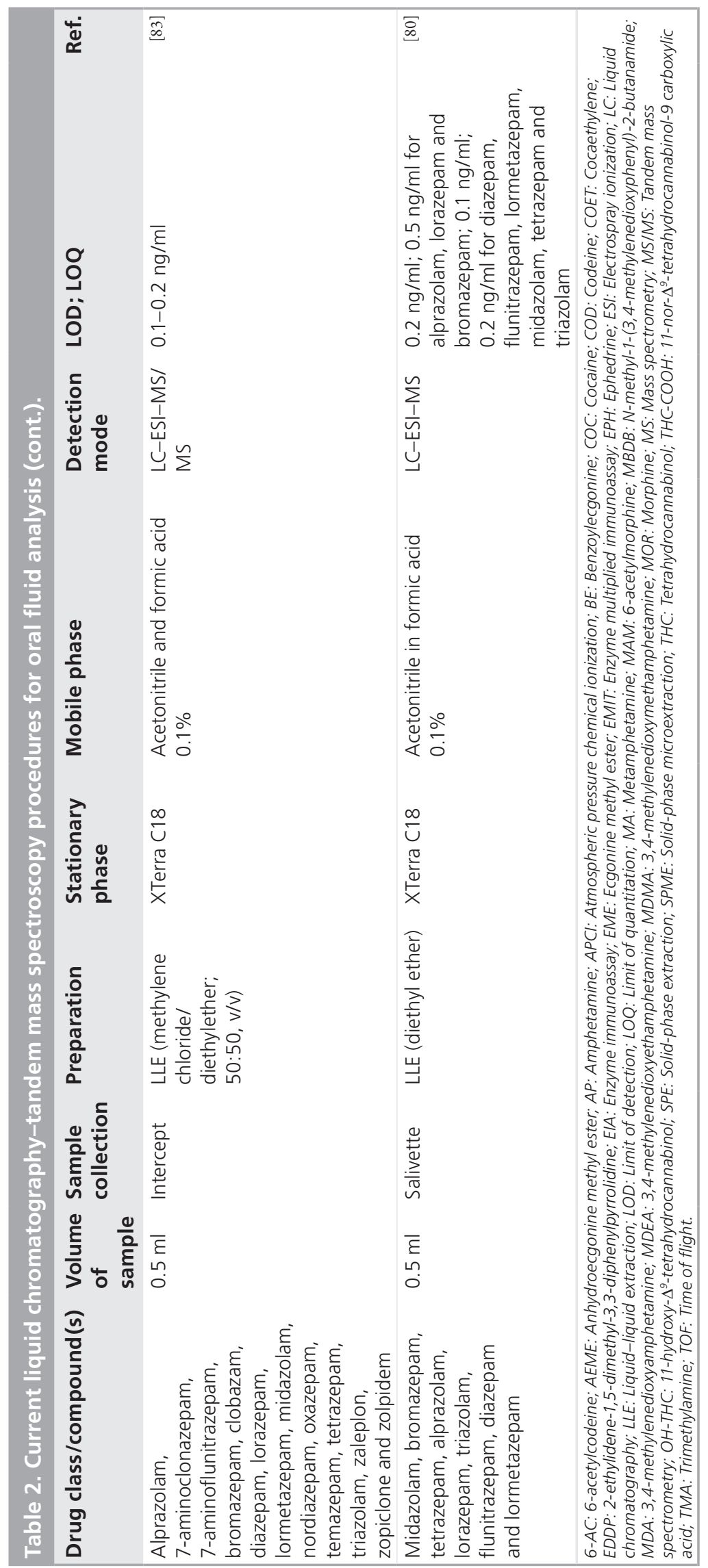




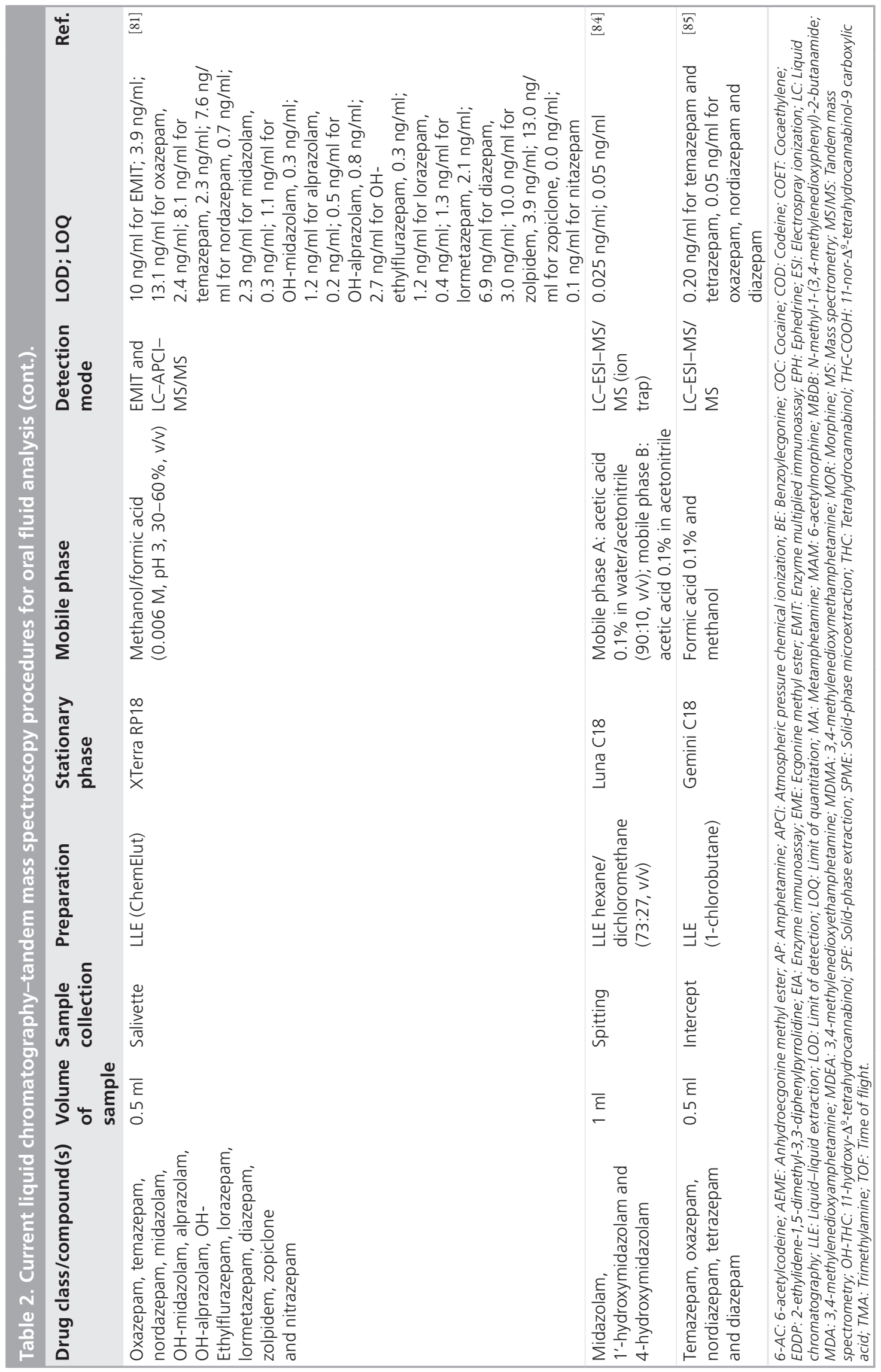




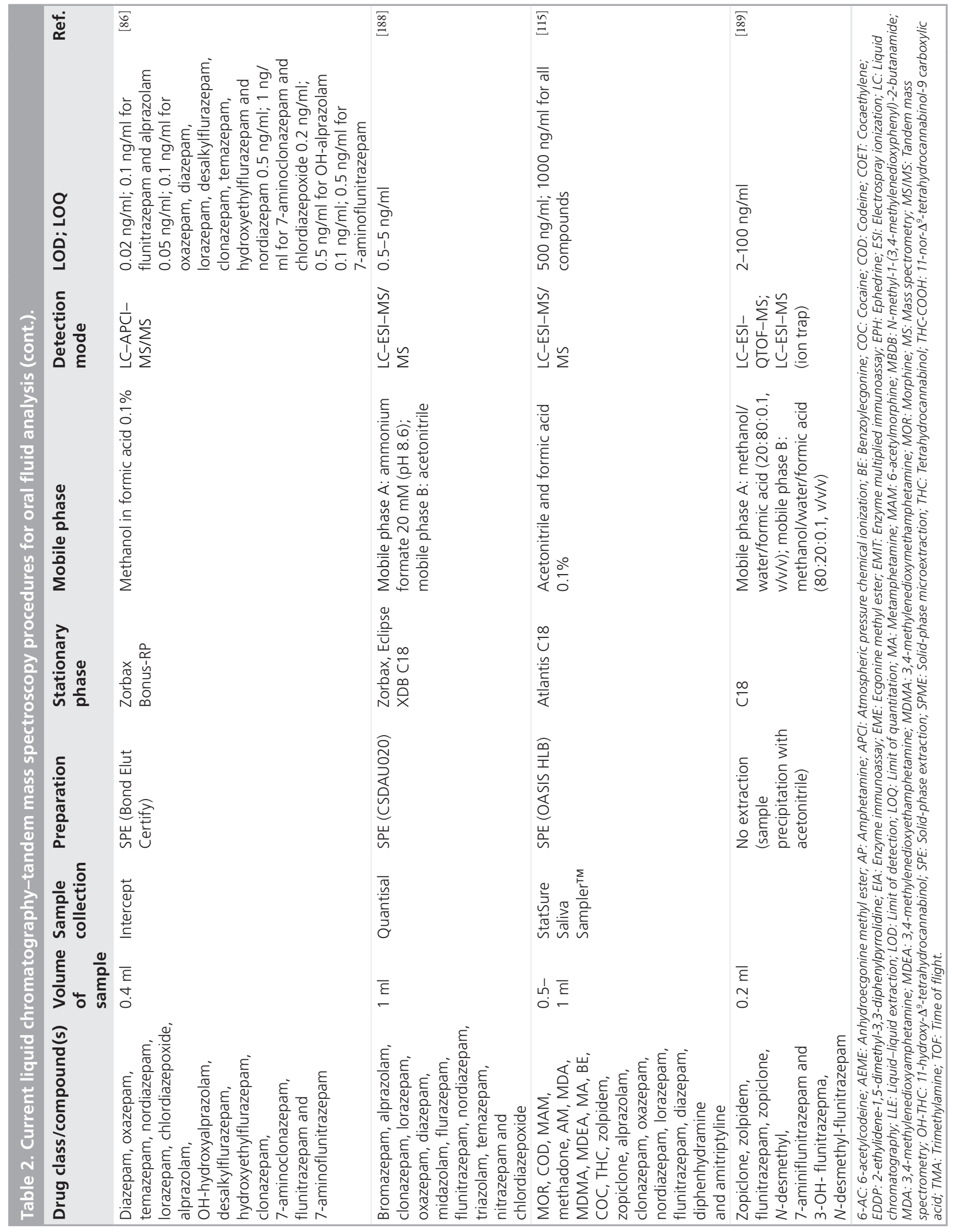




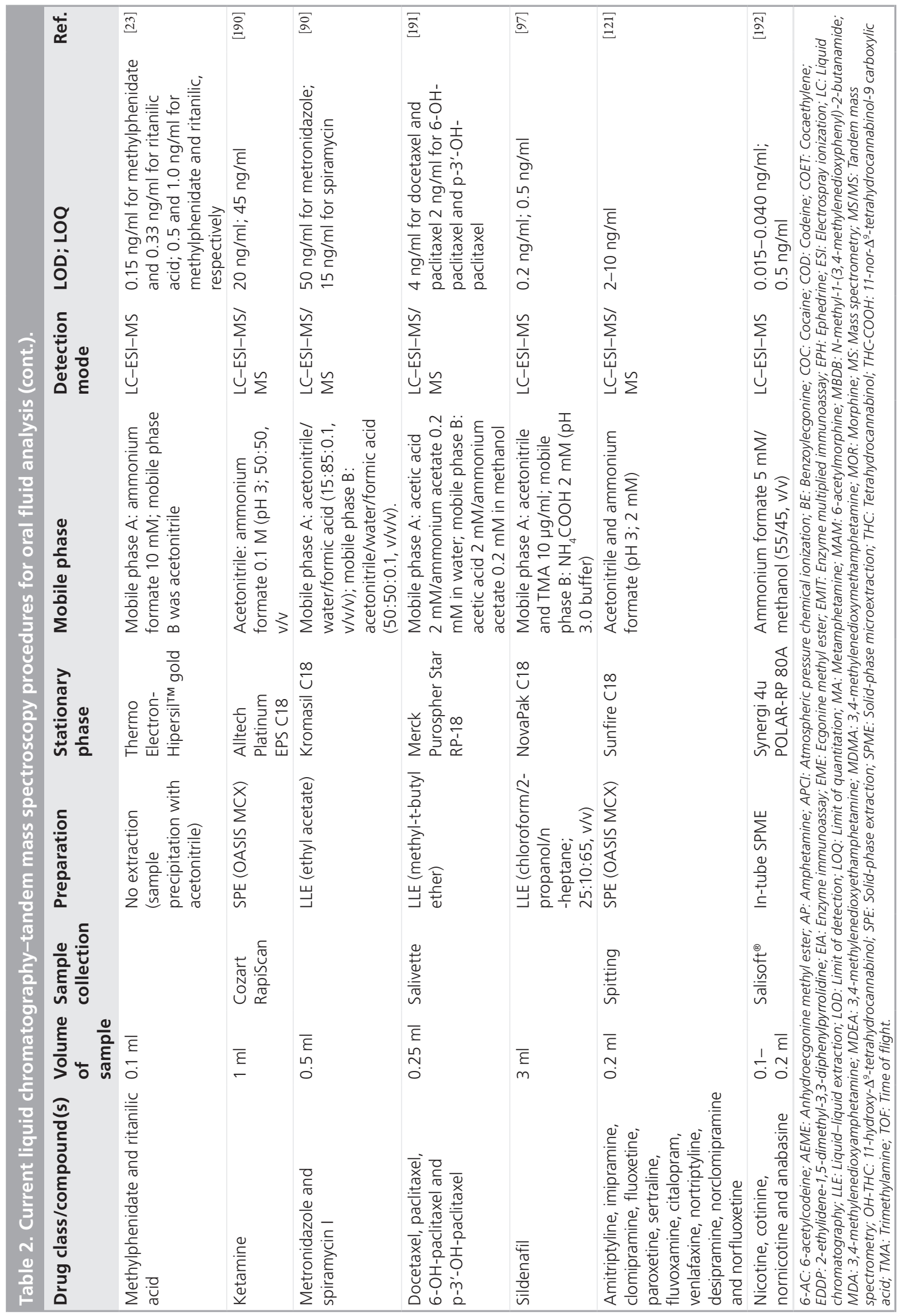


reported and, despite the small injection volume, occasional specimens had reduced signal, which was possibly due to ion suppression from oral fluid interferences.

An approach to improve laboratory throughput and analyze a large number of analytes in a single run is to use ultraperformance liquid chromatography (UPLC) systems, which employ particle diameters as small as $1.5 \mu \mathrm{m}$ and operating pressures higher than 5000 psi. However, despite having several applications in the field of toxicology [164,176-179], this technology has scarce application in oral fluid analysis [180].

However, identification of unknowns is a hard task for LC-MS/MS instruments. This can be overcome by the use of time-of-flight (TOF) mass spectrometers, which allow accurate mass measurement. This determination is performed by measuring flight time after acceleration in a vacuum tube by high voltage, and ion paths in the order of $2 \mathrm{~m}$ with flight times of $5-100 \mu \mathrm{s}$ allow rapid and accurate time measurements. This results in short analysis times, accurate mass measurements and large dynamic ranges.

The elemental formula can be determined from molecular mass, and interpretation is usually unambiguous. Indeed, there are reports on the reduction of choices to two or three unknown substances using a library of 7640 compounds without considering LC retention times [147]. The application of TOF technology to oral fluid specimens is reported in studies such as those by Clauwaert et al. [79] for the determination of cocaine and metabolites in oral fluid, by Mortier et al. [61] for amphetamines, opiates and cocaine, and by Quintela et al. [69] for cannabinoids.

Liquid chromatography-MS/MS-based methods are the state-of-the-art in analyzing oral fluid samples, due to the high sensitivity and specificity provided, and there has been a considerable number of published papers on the topic, which are summarized in TABLE 2.

\section{Conclusion \& future perspective}

Oral fluid testing is becoming more and more important in analytical toxicology, namely in the fields of clinical and forensic toxicology. Indeed, sample collection is performed easily in a noninvasive matter and, if necessary, under close supervision. This brings several advantages, including the cooperation of the person being analyzed and the difficulty in sample substitution or adulteration. One of the most prominent issues concerning the use of this biological specimen is that it can provide the ability to assess situations of driving under the influence of drugs, to which the development of easy-to-use on-site collection devices has contributed. Indeed, this type of instrument can provide a result within minutes of sample collection, which should be confirmed afterwards in laboratorial analysis.

This laboratorial analysis is only possible due to the huge improvement in analytical technologies seen over the last two decades, including both screening and confirmatory techniques. None of these techniques should be regarded as the 'unique solution to all the problems'. On the contrary, these techniques complement each other and, currently, their use is common in most laboratories.

Still, analytical instruments are becoming more sensitive and specific, which enables both drug detection and quantitation in very low amounts, and analyses where concentrations are expected to be low, as occurs in oral fluid. While the main analytical problems are adequately dealt with, more investigation is needed, namely on the establishment of saliva-to-plasma ratios of several drugs, aiding result interpretation.

In general, biological matrices are complex, as is oral fluid. Therefore, despite the high selectivity presented by analytical instruments, it is generally mandatory that the samples are thoroughly cleaned-up before chromatographic analysis can be performed. In addition, ion-suppression/ enhancement effects should be comprehensively studied, since the precision and accuracy of the method may be compromised. This may be a problem in terms of detection limits, which represent a very important issue when analyzing oral fluid, since, in most situations, the amount of available sample is small.

No one knows what the future holds for oral fluid analysis, but it is expected that analytical equipment will become more sensitive and miniaturization will be a reality. In fact, the concept of a system with small specimen size, low detection limits, multiple drug testing platforms and high throughput is promising.

\section{Financial \& competing interests disclosure}

The authors have no relevant affiliations or financial involvement with any organization or entity with a financial interest in or financial conflict with the subject matter or materials discussed in the manuscript. This includes employment, consultancies, honoraria, stock ownership or options, expert testimony, grants or patents received or pending, or royalties.

No writing assistance was utilized in the production of this manuscript. 


\section{Physiology \& mechanisms of drug incorporation}

- Drug incorporation can occur by passive diffusion through the membrane, active processes against a concentration gradient, filtration through pores in the membrane and pinocytosis.

- Drug incorporation is $\mathrm{pH}$ dependent.

- Little $\Delta^{9}$-tetrahydrocannabinol (THC; main constituent of cannabis) is secreted into saliva and, therefore, the majority of THC found in oral fluid originates from a deposit after smoking.

- The parent drug is the main compound detected in oral fluid, rather than its metabolites.

- Passive contamination is possible by exposure to an environment where drugs are being consumed by others.

\section{Collection procedures \& devices}

- The collection of saliva after stimulating its production can alter drug concentrations in this specimen.

- Saliva can be easily obtained without stimulation by spitting or the draining method.

- The recovery of drugs from the collection devices is concentration dependent and varies according to the analyte and collection device.

- Drug stability in the matrix should be studied, since it can affect the utility of the collection process.

\section{Applicability of oral fluid analysis}

- Oral fluid can be used to assess an individual's exposure to virtually every class of compounds, but drugs of abuse are by far the most detected substances.

- Analytical applications of oral fluid include therapeutic drug monitoring, pharmacokinetic studies, workplace medicine and detection of illicit drugs in driving situations.

\section{Analytical technologies}

- On-site collection devices

- On-site portable devices can be used for the assessment of drug-impaired driving situations. The advantages of on-site testing are rapid turnaround times, reduced costs and the fact that the test can be carried out virtually anywhere.

- Several studies have been conducted in the EU and USA to assess the utility of oral fluid analysis in driving situations.

- Immunoassays

- Immunoassays are extremely useful, since they allow the saving of time and money, which would be wasted in more expensive confirmatory methods (usually mass spectrometric-based techniques), while most of the samples would be negative.

- Immunoassays are in general aimed at the parent compound.

- The presumptive positive samples must be confirmed by more specific techniques, namely mass spectrometric methods.

- Their poor sensitivity for low-dose compounds, such as flunitrazepam, might still be a problem.

- Gas chromatography-mass spectrometry (GC-MS)

- GC-MS has been the most utilized technique for the confirmation of a number of organic compounds, mainly due to the availability of spectral libraries for drugs and metabolites.

- GC-MS is currently available in most laboratories, and this is still the main technique for confirmation and quantitation of drugs and their metabolites in biological specimens, including the so-called 'alternative' specimens, such as oral fluid, hair and sweat.

- The limits obtained when GC-MS-based techniques are used present a limitation in terms of oral fluid, mainly due to little sample availability for analysis.

- One possibility to overcome this problem is the use of tandem mass spectrometry.

- Liquid chromatography-mass spectrometry (LC-MS)

- LC-MS permits the analysis of nonvolatile, labile and/or high-molecular-weight compounds.

- Electrospray ionization (ESI) and atmospheric pressure chemical ionization (APCI) have become the most widespread ionization techniques.

- LC-MS is highly susceptible to matrix effects (ion suppression or enhancement), and these must be assessed during method development and validation.

- Tandem mass spectrometry improves the detection limits.

- The use of time-of-flight mass spectrometers, which allow accurate mass measurement, allows the identification of unknowns.

\section{Bibliography}

1 Horning MG, Brown L, Nowlin J, Lertratanangkoon K, Kellaway P, Zion TE. Use of saliva in therapeutic drug monitoring. Clin. Chem. 23, 157-164 (1977).

$>_{2}$ Gallardo E, Queiroz JA. The role of alternative specimens in toxicological analysis. Biomed. Chromatogr. 22, 795-821 (2008).
3 Spiehler V. Drugs in saliva. In: Clarke's Analysis of Drugs and Poisons. Pharmaceutical Press, London, UK, 109-123 (2004).

4 Drummer OH. Review: pharmacokinetics of illicit drugs in oral fluid. Forensic Sci. Int. 150, 133-142 (2005).

Wong RC, Tran M, Tung JK. Oral fluid drug tests: effects of adulterants and foodstuffs. Forensic Sci. Int. 150, 175-180 (2005).
-6 Huestis MA, Cone EJ. Relationship of $\Delta$-9-tetrahydrocannabinol concentrations in oral fluid and plasma after controlled administration of smoked cannabis. J. Anal. Toxicol. 28, 394-399 (2004).

7 Cook CE, Jeffcoat AR, Hill JM et al. Pharmacokinetics of methamphetamine self-administered to human subjects by smoking $S-(+)$ - methamphetamine 
hydrochloride. Drug Metab. Dispos. 21, 717-723 (1993).

8 Drummer OH. Introduction and review of collection techniques and applications of drug testing of oral fluid. Ther. Drug Monit. 30, 203-206 (2008).

- Aps JKM, Martens LC. The physiology of saliva and transfer of drugs into saliva. Forensic Sci. Int. 150, 119-131 (2005).

10 Kintz P, Samyn N. Unconventional samples and alternative matrices. In: Handbook of Analytical Separations (Volume 2). Bogusz MJ (Ed.). Elsevier Science, Amsterdam, The Netherlands, 459-488 (2000).

11 Crouch DJ, Day J, Baudys J. Evaluation of saliva/oral fluid as an alternate drug testing specimen - final report. National Institute of Standards and Technology (NISTR 7139. Gaitherburg, MD, USA, 1-70 (2004).

$\checkmark 12$ Drummer OH. Drug testing in oral fluid. Clin. Biochem. Rev. 27, 147-159 (2006).

13 Höld KM, De Boer D, Zuidema J, Maes RAA. Saliva as an analytical tool in toxicology. Int. J. Drug Testing. 1, 1-36 (1996).

14 Paxton JW. Measurement of drugs in saliva: a review. Methods Find Exp. Clin. Pharmacol. 1, 11-21 (1979).

15 DiGregorio GJ, Piraino AJ, Ruch E. Diazepam concentrations in parotid saliva, mixed saliva, and plasma. Clin. Pharmacol. Ther. 24, 720-725 (1978).

16 de Gier JJ, 't Hart BJ, Nelemans FA, Bergman H. Psychomotor performance and real driving performance of outpatients receiving diazepam. Psychopharmacology (Berl). 73, 340-344 (1981).

17 Perez-Reyes M. Marijuana smoking: factors that influence the bioavailability of tetrahydrocannabinol. In: Research Findings on Smoking of Abused Substances. Chiang CN, Hawks RL (Eds). NIDA Res Monogr. \#99, MD, USA, 42-62 (1990).

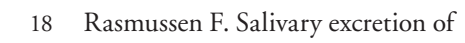
sulphonamides and barbiturates by cows and goats. Acta Pharmacol. Toxicol. (Copenh) 21, 11-19 (1964).

19 Kauert GF, Ramaekers JG, Schneider E, Moeller MR, Toennes SW. Pharmacokinetic properties of $\Delta$ 9-tetrahydrocannabinol in serum and oral fluid. J. Anal. Toxicol. 31, 288-293 (2007).

-20 Kim I, Barnes AJ, Oyler JM et al. Plasma and oral fluid pharmacokinetics and pharmacodynamics after oral codeine administration. Clin. Chem. 48, 1486-1496 (2002).

-21 Huestis MA, Cone EJ. Methamphetamine disposition in oral fluid, plasma, and urine. Ann. NY Acad. Sci. 1098, 104-121 (2007).
-22 Mecarelli OM, Voti PLM, Pro SM et al. Saliva and serum levetiracetam concentrations in patients with epilepsy. Ther. Drug Monit. 29, 313-318 (2007).

23 Marchei E, Farr FM, Pellegrini M et al. Liquid chromatography-electrospray ionization mass spectrometry determination of methylphenidate and ritalinic acid in conventional and non-conventional biological matrices. J. Pharm. Biomed. Anal. 49, 434-439 (2009).

$\checkmark 24$ de Castro A, Concheiro M, Quintela O, Cruz A, López-Rivadulla M. LC-MS/MS method for the determination of nine antidepressants and some of their main metabolites in oral fluid and plasma Study of correlation between venlafaxine concentrations in both matrices. J. Pharm. Biomed. Anal. 48, 183-193 (2008).

25 Langman LJ. The use of oral fluid for therapeutic drug management: clinical and forensic toxicology. Ann. NY Acad. Sci. 1098, 145-166 (2007).

26 Pil K, Verstraete A. Current Developments in drug testing in oral fluid. Ther. Drug Monit. 30, 196-202 (2008).

-27 Verstraete AG, Pierce A. Workplace drug testing in Europe. Forensic Sci. Int. 121, 2-6 (2001).

28 Cone EJ. Oral fluid testing: new technology enables drug testing without embarrassment. J. Calif. Dent. Assoc. 34, 311-315 (2006).

29 Crouch DJ. Oral fluid collection: the neglected variable in oral fluid testing. Forensic Sci. Int. 150, 165-173 (2005).

30 Mucklow JC, Bending MR, Kahn GC, Dollery CT. Drug concentration in saliva. Clin. Pharmacol. Ther. 24, 563-570 (1978).

31 Jones AW. Measuring ethanol in saliva with the QED1 enzymatic test device: comparison of results with blood and breath-alcohol concentrations. J. Anal. Toxicol. 19, 169-174 (1995).

32 Dabbs JM. Salivary testosterone measurements: collecting, storing and mailing saliva samples. Physiol. Behav. 49, 815-817 (1991).

33 Navazesh M. Methods for collecting saliva. Ann. NY Acad. Sci. 694, 72-77 (1993).

34 Chang K. Interactions between drugs and saliva-stimulating parafilm and their implications in measurements of saliva drug levels. Res. Commun. Chem. Pathol. Pharmacol. 13, 357-360 (1976).

-35 Navarro M, Pichini S, Farre M et al. Usefulness of saliva for measurement of 3,4-methoxymethamphetamine and its metabolites: correlation with plasma drug concentrations and effect of salivary $\mathrm{pH}$. Clin. Chem. 47, 1788-1794 (2001).
36 O’Neal CL, Crouch DJ, Rollins DE, Fatah AA. The effects of collection methods on oral fluid codeine concentrations. J. Anal. Toxicol. 24, 536-542 (2000).

-37 Schepers RJ, Oyler JM, Joseph RE Jr, Cone EJ, Moolchan ET, Huestis MA. Methamphetamine and amphetamine pharmacokinetics in oral fluid and plasma after controlled oral methamphetamine administration to human volunteers. Clin. Chem. 49, 121-132 (2003).

-38 Kato K, Hillsgrove M, Weinhold L, Gorelick DA, Darwin WD, Cone EJ. Cocaine and metabolite excretion in saliva under stimulated and nonstimulated conditions. J. Anal. Toxicol. 17, 338-341 (1993).

-39 Langel K, Engblom C, Pehrsson A, Gunnar T, Ariniemi K, Lillsunde P. Drug testing in oral fluid-evaluation of sample collection devices. J. Anal. Toxicol. 32, 393-401 (2008).

40 Dickson S, Park A, Nolan S et al. The recovery of drugs from oral fluid collection devices. Forensic Sci. Int. 165, 78-84 (2007).

41 Kauert GF, Iwersen-Bergmann S, Toennes SW. Assay of $\Delta 9$-tetrahydrocannabinol (THC) in oral fluid-evaluation of the OraSure oral specimen collection device. J. Anal. Toxicol. 30, 274-277 (2006).

42 Chee KY, Lee D, Naidoo BD, Bye A. A simple collection method for saliva in children: potential for home monitoring of carbamazepine therapy. Br. J. Clin. Pharmacol. 35, 311-313 (1993).

43 Lamey PJ, Nolan A. The recovery of human saliva using the Salivette system. Eur. J. Clin. Chem. Clin. Biochem. 32, 727-728 (1994).

44 Samyn N, Laloup M, De Boeck G. Bioanalytical procedures for determination of drugs of abuse in oral fluid. Anal. Bioanal. Chem. 388, 1437-1454 (2007).

45 Dams R, Choo RE, Lambert WE, Jones H, Huestis MA. Oral fluid as an alternative matrix to monitor opiate and cocaine use in substance-abuse treatment patients. Drug Alcohol Depend. 87, 258-267 (2007).

46 Crouch DJ, Walsh JM, Flegel R, Cangianelli L, Baudys J, Atkins R. An evaluation of selected oral fluid point-ofcollection drug-testing devices. J. Anal. Toxicol. 29, 244-248 (2005).

-47 Drummer OH, Gerostamoulos D, Chu M, Swann P, Boorman M, Cairns I. Drugs in oral fluid in randomly selected drivers. Forensic Sci. Int. 170, 105-110 (2007).

48 Quintela O, Crouch DJ, Andrenyak DM. Recovery of drugs of abuse from the Immunalysis Quantisal ${ }^{\mathrm{TM}}$ oral fluid collection device. J. Anal. Toxicol. 30, 614-616 (2006). 
-49 Gunnar T, Ariniemi K, Lillsunde P. Validated toxicological determination of 30 drugs of abuse as optimized derivatives in oral fluid by long column fast gas chromatography/electron impact mass spectrometry. J. Mass Spectrom. 40, 739-753 (2005).

- 50 Øiestad EL, Johansen U, Christophersen S. Drug screening of preserved oral fluid by liquid chromatography-tandem mass spectrometry. Clin. Chem. 53, 300-309 (2007).

- 51 Cámpora P, Bermejo AM, Tabernero MJ, Fernandez P. Quantitation of cocaine and its major metabolites in human saliva using gas chromatography-positive chemical ionization-mass spectrometry (GC-PCIMS). J. Anal. Toxicol. 27, 270-274 (2003).

\52 Cámpora P, Bermejo AM, Tabernero MJ, Fernandez P. Use of gas chromatography/mass spectrometry with positive chemical ionization for the determination of opiates in human oral fluid. Rapid Commun. Mass Spectrom. 20, 1288-1292 (2006).

-53 Quintela O, Cruz A, Concheiro M, de Castro A, López-Rivadulla M. A sensitive, rapid and specific determination of midazolam in human plasma and saliva by liquid chromatography/electrospray mass spectrometry. Rapid Commun. Mass Spectrom. 18, 2976-2982 (2004).

54 Niedbala RS, Kardos KW, Fritch DF et al. Detection of marijuana use by oral fluid and urine analysis following single-dose administration of smoked and oral marijuana. J. Anal. Toxicol. 25, 289-303 (2001).

- 55 Concheiro M, de Castro A, Quintela O, López-Rivadulla M, Cruz A. Determination of MDMA, MDA, MDEA and MBDB in oral fluid using high performance liquid chromatography with native fluorescence detection. Forensic Sci. Int. 150, 221-226 (2005).

56 Moore C, Vincent M, Rana S, Coulter C, Agrawal A, Soares J. Stability of $\Delta(9)$ tetrahydrocannabinol (THC) in oral fluid using the Quantisal ${ }^{\mathrm{TM}}$ collection device. Forensic Sci. Int. 164, 126-130 (2006).

57 Niedbala RS, Kardos K, Fries T, Cannon A, Davis A. Immunoassay for detection of cocaine/metabolites in oral fluids. J. Anal. Toxicol. 25, 62-68 (2001).

-58 Samyn N, De Boeck G, Cirimele V, Verstraete A, Kintz P. Detection of flunitrazepam and 7-aminoflunitrazepam in oral fluid after controlled administration of rohypnol. J. Anal. Toxicol. 26, 211-215 (2002).

-59 Niedbala RS, Kardos K, Waga J et al. Laboratory analysis of remotely collected oral fluid specimens for opiates by immunoassay. J. Anal. Toxicol. 25, 310-315 (2001).
-60 Cooper G, Wilson L, Reid C, Baldwin D, Hand C, Spiehler V. Validation of the Cozart microplate EIA for analysis of opiates in oral fluid. Forensic Sci. Int. 154, 240-246 (2005).

-61 Mortier KA, Maudens KE, Lambert WE et al. Simultaneous, quantitative determination of opiates, amphetamines, cocaine and benzoylecgonine in oral fluid by liquid chromatography quadrupole-time-offlight mass spectrometry. J. Chromatogr. B Analyt. Technol. Biomed. Life Sci. 779, 321-330 (2002).

62 Speckl IM, Hallbach J, Guder WG, Meyer LV, Zilker T. Opiate detection in saliva and urine-a prospective comparison by gas chromatography-mass spectrometry. J. Toxicol. Clin. Toxicol. 37, 441-445 (1999).

63 Samyn N, van Haeren C. On-site testing of saliva and sweat with Drugwipe and determination of concentrations of drugs of abuse in saliva, plasma and urine of suspected users. Int. J. Legal Med. 113, 150-154 (2002).

64 Jones J, Tomlinson K, Moore C. The simultaneous determination of codeine, morphine, hydrocodone, hydromorphone, 6-acetylmorphine, and oxycodone in hair and 74 oral fluid. J. Anal. Toxicol. 26, 171-175 (2000).

-65 Phillips SG, Allen KR. Acetylcodeine as a marker of illicit heroin abuse in oral fluid samples. J. Anal. Toxicol. 30, 370-374 (2006).

-66 Day D, Kuntz DJ, Feldman M, Presley L. Detection of THCA in oral fluid by GC-MS/ MS. J. Anal. Toxicol. 30, 645-650 (2006).

- 67 Moore C, Ross W, Coulter C et al. Detection of the marijuana metabolite 11-nor- $\Delta^{9}$ tetrahydrocannabinol-9-carboxylic acid in oral fluid specimens and its contribution to positive results in screening assays. J. Anal. Toxicol. 30, 413-418 (2006).

-68 Moore C, Rana S, Coulter C. Simultaneous identification of 2-carboxytetrahydrocannabinol, tetrahydrocannabinol, cannabinol and cannabidiol in oral fluid. J. Chromatogr. B Analyt. Technol. Biomed. Life Sci. B 852, 459-464 (2007).

-69 Quintela O, Andrenyak DM, Hoggan MH, Crouch DJ. A validated method for the detection of $\Delta^{9}$-tetrahydrocannabinol and 11-nor-9-carboxy- $\Delta^{9}$-tetrahydrocannabinol in oral fluid samples by liquid chromatography coupled with quadrupole-time-of-flight mass spectrometry. J. Anal. Toxicol. 31, 157-164 (2007).

70 Concheiro M, de Castro A, Quintela O, Cruz A, López-Rivadulla M. Development and validation of a method for the quantitation of $\Delta 9$ tetrahydrocannabinol in oral fluid by liquid chromatography electrospray-mass-spectrometry.

J. Chromatogr. B Analyt. Technol. Biomed. Life Sci. B 810, 319-324 (2005).

71 Laloup M, Ramirez Fernandez MM, Wood M, de Boeck G, Maes V, Samyn N. Quantitative analysis of

$\Delta^{9}$-tetrahydrocannabinol in preserved oral fluid by liquid chromatography-tandem mass spectrometry. J. Chromatogr. B Analyt. Technol. Biomed. Life Sci. A 1082, 15-24 (2004).

72 Scheidweiler KB, Huestis MA. A validated gas chromatographic-electron impact ionization mass spectrometric method for methylenedioxymethamphetamine (MDMA), methamphetamine and metabolites in oral fluid. J. Chromatogr. B Analyt. Technol. Biomed. Life Sci. B 835, 90-99 (2006).

-73 Peters FT, Samyn N, Kraemer T, Riedel WJ, Maurer HH. Negative-ion chemical ionization gas chromatography-mass spectrometry assay for enantioselective measurement of amphetamines in oral fluid: application to a controlled study with MDMA and driving under the influence cases. Clin. Chem. 53, 702-710 (2007).

Wilson L, Jehanli A, Hand C, Cooper G, Smith R. Evaluation of a rapid oral fluid point-of-care test for MDMA. J. Anal. Toxicol. 31, 98-104 (2007).

-75 Engblom C, Gunnar T, Rantanen A, Lillsunde P. Driving under the influence of drugs-amphetamine concentrations in oral fluid and whole blood samples. J. Anal. Toxicol. 31, 276-280 (2007).

76 Samyn N, De Boeck G, Wood M et al. Plasma, oral fluid and sweat wipe ecstasy concentrations in controlled and real life conditions. Forensic Sci. Int. 128, 90-97 (2002).

77 Wood M, De Boeck G, Samyn N et al. Development of a rapid and sensitive method for the quantitation of amphetamines in human plasma and oral fluid by LC-MS/MS J. Anal. Toxicol. 27, 78-87 (2003).

Jufer R, Walsh SL, Cone EJ, Sampson-Cone A. Effect of repeated cocaine administration on detection times in oral fluid and urine. J. Anal. Toxicol. 30, 458-462 (2006).

79 Clauwaert K, Decaestecker T, Mortier K et al. The determination of cocaine, benzoylecgonine, and cocaethylene in small-volume oral fluid samples by liquid chromatography-quadrupole-time of- flight mass spectrometry. J. Anal. Toxicol. 28, 655-659 (2004).

80 Quintela O, Cruz A, Castro A, Concheiro M, López-Rivadulla M. Liquid chromatographyelectrospray ionisation mass spectrometry for the determination of nine selected 
benzodiazepines in human plasma and oral fluid. J. Chromatogr. B Analyt. Technol. Biomed. Life Sci. 825, 63-71 (2005).

-81 Smink BE, Mathijssen MPM, Lusthof KJ, de Gier JJ, Egberts ACG, Uges DRA. Comparison of urine and oral fluid as matrices for screening of thirty-three benzodiazepines and benzodiazepine-like substances using immunoassay and LCMS(-MS). J. Anal. Toxicol. 30, 478-485 (2006).

82 Kintz P, Villain M, Cirimele V, Pepin G, Ludes B. Windows of detection of lorazepam in urine, oral fluid and hair, with a special focus on drug-facilitated crimes. Forensic Sci. Int. 145, 131-135 (2004).

83 Kintz P, Villain M, Concheiro M, Cirimele V. Screening and confirmatory method for benzodiazepines and hypnotics in oral fluid by LC-MS/MS. Forensic Sci. Int. 150, 213-220 (2005).

84 Link B, Haschke M, Wenk M, Krahenbuhl S. Determination of midazolam and its hydroxy metabolites in human plasma and oral fluid by liquid chromatography/electrospray ionization ion trap tandem mass spectrometry. Rapid Commun. Mass Spectrom. 21, 1531-1540 (2007).

-85 Laloup M, Fernandez MM, Wood M et al. Detection of diazepam in urine, hair and preserved oral fluid samples with LC-MS/MS after single and repeated administration of Myolastan and Valium. Anal. Bioanal. Chem. 388, 1545-1556 (2007).

86 Ngwa G, Frich D, Blum K, Newland G. Simultaneous analysis of 14 benzodiazepines in oral fluid by solid-phase extraction and LC-MS/MS. J. Anal. Toxicol. 31, 369-376 (2007).

87 Concheiro M, Villain M, Bouchet S, Ludes B, Lopez-Rivadulla M, Kintz P. Windows of detection of tetrazepam in urine, oral fluid, beard, and hair, with a special focus on drug-facilitated crimes. Ther. Drug Monit. 27, 565-570 (2005).

-88 Brenneisen R, Elsohly MA, Murphy TP et al. Pharmacokinetics and excretion of $\gamma$-hydroxybutyrate (GHB) in healthy subjects. J. Anal. Toxicol. 28, 625-630 (2004).

-89 Abanades S, Farré M, Segura M et al. Disposition of gamma-hydroxybutyric acid in conventional and nonconventional biologic fluids after single drug administration: issues in methodology and drug monitoring. Ther. Drug Monit. 29, 64-70 (2007).

90 Sagan C, Salvador A, Dubreuil D, Poulet PP, Duffaut D, Brumpt I. Simultaneous determination of metronidazole and spiramycin I in human plasma, saliva and gingival crevicular fluid by LC-MS/MS. J. Pharm. Biomed. Anal. 38, 298-306 (2005).

-91 Rana S, Moore C, Vincent M, Coulter C, Agrawal A, Soares J. Determination of propoxyphene in oral fluid. J. Anal. Toxicol. 30, 516-518 (2006).

-92 Moore C, Rana S, Coulter C. Determination of meperidine, tramadol and oxycodone in human oral fluid using solid phase extraction and gas chromatography-mass spectrometry. J. Chromatogr. B Analyt. Technol. Biomed. Life Sci. 850, 370-375 (2007).

93 Rodrigues WC, Wang G, Moore C, Agrawal A, Vincent MJ, Soares JR. Development and validation of ELISA and GC-MS procedures for the quantification of dextromethorphan and its main metabolite dextrorphan in urine and oral fluid. J. Anal. Toxicol. 28, 220-226 (2008).

-94 Toraño JS, van Kan HJ. Simultaneous determination of the tobacco smoke uptake parameters nicotine, cotinine and thiocyanate in urine, saliva and hair, using gas chromatography-mass spectrometry for characterisation of smoking status of recently exposed subjects. Analyst. 128, 838-843 (2003).

-95 Kim I, Wtsadik A, Choo RE, Jones HE, Huestis MA. Usefulness of salivary trans-3'-hydroxycotinine concentration and trans-3'-hydroxycotinine/cotinine ratio as biomarkers of cigarette smoke in pregnant women. J. Anal. Toxicol. 29, 689-695 (2005).

$\$ 96$ Paul BD, Smith ML. Cyanide and thiocyanate in human saliva by gas chromatography-mass spectrometry. J. Anal. Toxicol. 30, 511-515 (2006).

97 Tracqui A, Ludes B. HPLC-MS for the determination of sildenafil citrate (Viagra) in biological fluids. Application to the salivary excretion of sildenafil after oral intake. J. Anal. Toxicol. 27, 88-94 (2003).

Bennett GA, Davies E, Thomas P. Is oral fluid analysis as accurate as urinalysis in detecting drug use in a treatment setting? Drug Alcohol Depend. 72, 265-269 (2003).

-99 Neale J, Robertson M. Comparisons of self-report data and oral fluid testing in detecting drug use amongst new treatment clients. Drug Alcohol Depend. 71, 57-64 (2003).

100 Huestis MA. Pharmacokinetics and metabolism of the plant cannabinoids, delta9-tetrahydrocannabinol, cannabidiol and cannabinol. Handb. Exp. Pharmacol. 168, 657-690 (2005).

-101 Walsh MJ. New technology and new initiatives in U.S. wokplace testing. Forensic Sci. Int. 174, 120-124 (2008).
- 102 Caplan YH, Goldberger BA. Alternative specimens for workplace drug testing. J. Anal. Toxicol. 25, 396-399 (2001).

103 Verstraete AG. Oral fluid testing for driving under the influence of drugs: history, recent progress and remaining challenges. Forensic Sci. Int. 150, 143-150 (2005).

104 Samyn N, De Boeck G, Verstraete AG. The use of oral fluid and sweat wipes for the detection of drugs of abuse in drivers. J. Forensic Sci. 47, 1380-1387 (2002).

105 Kintz P, Bernhard W, Villain M, Gasser M, Aebi B, Cirimele V. Detection of cannabis use in drivers with the Drugwipe device and by GC-MS after Intercept ${ }^{\circledR}$ device collection. J. Anal. Toxicol. 28, 724-727 (2005).

106 Toennes SW, Kauert GF, Steinmeyer S, Moeller MR. Driving under the influence of drugs - evaluation of analytical data of drugs in oral fluid, serum and urine, and correlation with impairment symptoms. Forensic Sci. Int. 152, 149-155 (2005)

107 Wylie FM, Torrance H, Seymour A, Buttress S, Oliver JS. Drugs in oral fluid part II. Investigation of drugs in drivers. Forensic Sci. Int. 150, 199-204 (2005).

108 Laloup M, Ramirez Fernandez MM, Wood M, De Boeck G, Maes V, Samyn N. Correlation of $\Delta$ 9-tetrahydrocannabinol concentrations determined by LC-MS/MS in oral fluid and plasma from impaired drivers and evaluation of the on-site Drager DrugTest. Forensic Sci. Int. 161, 175-179 (2006).

109 Concheiro M, de Castro A, Quintela O, Cruz A, López-Rivadulla M. Confirmation by LC-MS of drugs in oral fluid obtained from roadside testing. Forensic Sci. Int. 170, 156-162 (2007).

110 Pehrsson A, Gunnar T, Engblom C, Seppa H, Jama A, Lillsunde P. Roadside oral fluid testing: comparison of the results of Drugwipe 5 and Drugwipe benzodiazepines on-site tests with laboratory confirmation results of oral fluid and whole blood. Forensic Sci. Int. 175, 140-148 (2008).

111 Kintz P, Cirimele V, Ludes B. Detection of cannabis in oral fluid (saliva) and forehead wipes (sweat) from impaired drivers. J. Anal. Toxicol. 24, 557-561 (2000).

-112 Gjerde H, Normann PT, Pettersen BS et al. Prevalence of alcohol and drugs among Norwegian motor vehicle drivers: a roadside survey. Accid. Anal. Prev. 40, 1765-1772 (2008).

3 Ramaekers JG, Moeller MR, van Ruitenbeek P, Theunissen EL, Schneider E, Kauert G. Cognition and motor control as a function of $\Delta$ 9-THC concentration in serum and oral fluid: Limits of impairment. Drug Alcohol Depend. 85, 114-122 (2006). 
114 Sergi M, Bafile E, Compagnone D, Curini R, D’Ascenzo G, Romolo F. Multiclass analysis of illicit drugs in plasma and oral fluids by LCMS/MS. Anal. Bioanal. Chem. 393, 709-718 (2009).

115 Concheiro M, de Castro A, Quintela O, Cruz A, López-Rivadulla M. Determination of illicit and medicinal drugs and their metabolites in oral fluid and preserved oral fluid by liquid chromatography-tandem mass spectrometry. Anal. Bioanal. Chem. 391, 2329-2338 (2008).

- 116 Wylie FM, Torrance H, Anderson RA, Oliver JS. Drugs in oral fluid: part I. Validation of an analytical procedure for licit and illicit drugs in oral fluid. Forensic Sci. Int. 150, 191-198 (2005).

- 117 Grönholm M, Lillsunde P. A comparison between on-site immunoassay drug-testing devices and laboratory results. Forensic Sci. Int. 121, 37-46 (2001).

- 118 Peace MR, Tarnai LD, Poklis A. Performance evaluation of four on-site drug-testing devices for detection of drugs of abuse in urine. J. Anal. Toxicol. 24, 589-594 (2000).

119 Siegel IA. The role of saliva in drug monitoring. Ann. NY Acad. Sci. 694, 86-90 (1993).

120 Cone EJ, Jenkins AJ. Saliva, drug analysis. In: Handbook of Analytical Therapeutic Drug Monitoring and Toxicology. Wong SHY, Sunshine I (Eds). CRC Press, London, UK (1997).

121 Samyn N, Verstraete A, van Haeren C, Kintz P. Analysis of drugs of abuse in saliva. Forensic Sci. Rev. 11, 1-19 (1999).

122 Biermann T, Schwarze B, Zedler B, Betz P. On-site testing of illicit drugs: the use of the drug-testing device "Toxiquick". Forensic Sci. Int. 143, 21-25 (2004).

- 123 Kacinko SL, Barnes AJ, Kim I et al. Performance characteristics of the Cozart ${ }^{\circledR}$ RapiScan Oral Fluid Drug Testing System for opiates in comparison to ELISA and GC/MS following controlled codeine administration. Forensic Sci. Int. 141, 41-48 (2004).

- 124 Barrett C, Good C, Moore C. Comparison of point of collection screening of drugs of abuse in oral fluid with a laboratory based urine screen. Forensic Sci. Int. 122, 163-166 (2001).

125 Pichini S, Navarro M, Farre M et al. On-site testing of 3,4methylenedioxymethamphetamine (ecstacy) in saliva with Drugwipe and Drugread: a controlled study in recreational users. Clin. Chem. 48, 174-176 (2002).

126 Kintz P, Brunet B, Muller JF et al. Evaluation of the Cozart DDSV test for cannabis in oral fluid. Ther. Drug Monit. 31, 131-134 (2009).
127 Walsh JM, Flegel R, Crouch DJ, Cangianelli L, Baudys J. An evaluation of rapid point-of collection oral fluid drugtesting devices. J. Anal. Toxicol. 27, 429-439 (2003).

128 Toennes SW, Steinmeyer S, Maurer H, Moeller MR, Kauert GF. Screening for drugs of abuse in oral fluid - correlation of analysis results with serum in forensic cases. J. Anal. Toxicol. 29, 22-27 (2005).

129 Hicks JM, Haeckel R, Price CP, Lewandrowski K, Wu AHB. Recommendations and opinions for the use of point-of-care testing for hospitals and primary care: summary of a 1999 symposium. Clin. Chim. Acta. 303, 1-17 (2001).

130 Moore C, Vincent M, Rana S, Coulter A, Agrawal A, Soares J. Stability of $\Delta 9$ tetrahydrocannabinol (THC) in oral fluid using the Quantisal ${ }^{\mathrm{TM}}$ collection device. Forensic Sci. Int. 164, 126-130 (2006).

131 Kelly E, Darke S, Ross J. A review of drug use and driving: epidemiology, impairment, risk factors and risk perceptions. Drug Alcohol Rev. 23, 319-344 (2004).

132 Crouch DJ, Walsh JM, Cangianelli L, Quintela O. Laboratory evaluation and field application of roadside oral fluid collectors and drug testing devices. Ther. Drug Monit. 30, 188-195 (2008).

133 Dolan K, Rouen D, Kimber JO. An overview of the use of urine, hair, sweat and saliva to detect drug use. Drug Alcohol Rev. 23, 213-217 (2004).

134 Barnes AJ, Kim I, Schepers R et al. Sensitivity, specificity, and efficiency in detecting opiates in oral fluid with the Cozart Opiate Microplate EIA and GC-MS following controlled codeine administration. J. Anal. Toxicol. 27, 402-407 (2003).

135 Cooper G, Wilson L, Reid C, Baldwin D, Hand C, Spiehler V. Comparison of GC-MS and EIA results for the analysis of methadone in oral fluid. J. Forensic Sci. 50, 928-932 (2005).

136 Cooper G, Wilson L, Reid C, Baldwin D, Main L, Hand C. Evaluation of the Cozart ${ }^{\circledR}$ RapiScan drug test system for opiates and cocaine in oral fluid. Forensic Sci. Int. 150, 239-243 (2005).

-137 Kim I, Barnes AJ, Schepers R et al. Sensitivity and specificity of the Cozart microplate EIA cocaine oral fluid at proposed screening and confirmation cutoffs. Clin. Chem. 49, 498-1503 (2003).

- 138 Cooper G, Wilson L, Reid C, Baldwin D, Hand C, Spieher V. Validation of the Cozart microplate EIA for cocaine and metabolites in oral fluid. J. Anal. Toxicol. 28, 498-503 (2004).
139 Kolbrich EA, Kim I, Barnes AJ et al. Cozart ${ }^{\circledR}$ RapiScan oral fluid drug testing system: an evaluation of sensitivity, specificity, and efficiency for cocaine detection compared with ELISA and GC-MS following controlled cocaine administration. J. Anal. Toxicol. 27, 407-411 (2003).

- 140 Laloup M, Tilman G, Maes V et al. Validation of an ELISA-based screening assay for the detection of amphetamine, MDMA and MDA in blood and oral fluid. Forensic Sci. Int. 153, 29-37 (2005).

141 Cooper G, Wilson L, Reid C, Hand C, Spiehler V. Validation of the Cozart ${ }^{\circledR}$ amphetamine microplate EIA for the analysis of amphetamines in oral fluid. Forensic Sci. Int. 159, 104-112 (2006).

- 142 Lin DL, Yin RM, Chen CH, Chen YL, Liu RH. Performance characteristics of 7-aminoflunitrazepam specific enzyme-linked immunosorbent assays. J. Anal. Toxicol. 29, 718-723 (2005).

143 Townsend S, Fanning L, O'Kennedy R. Salivary analysis of drugs - potential and difficulties. Anal. Lett. 41, 925-948 (2008).

144 Maurer HH. Current role of liquid chromatography-mass spectrometry in clinical and forensic toxicology. Anal. Bioanal. Chem. 388, 1315-1325 (2007).

145 Pfleger K, Maurer HH, Weber A. Mass Spectral Library of Drugs, Poisons, Pesticides, Pollutants and their Metabolites ( $3^{\text {rd }}$ Edition). Agilent Technologies, CA, USA (2000).

146 Quintela O, Cruz A, Concheiro M, de Castro A, López-Rivadulla M. Metodología LC-MS. Aspectos generales de la técnica y sus aplicaciones en el campo de la toxicología. Toxicol. Rev. 22, 7-14 (2005).

147 Smith ML, Vorce SP, Holler JM et al. Modern instrumental methods in forensic toxicology. J. Anal. Toxicol. 31, 237-253 (2007).

148 Cognard E, Bouchonnet S, Staub C. Validation of a gas chromatography-ion trap tandem mass spectrometry for simultaneous analyse of cocaine and its metabolites in saliva. J. Pharm. Biomed. Anal. 41, 925-934 (2006).

149 dos Santos Lucas AC, Bermejo A, Fernandez P, Tabernero MJ. Solid-phase microextraction in the determination of methadone in human saliva by gas chromatography-mass spectrometry. J. Anal. Toxicol. 24, 93-96 (2000).

150 Luo D, Chen F, Xiao K, Feng YQ. Rapid determination of $\Delta(9)$-tetrahydrocannabinol in saliva by polymer monolith microextraction combined with gas chromatography-mass spectrometry. Talanta 77, 1701-1706 (2009). 
-151 Wang VS, Lu MY. Application of solid-phase microextraction and gas chromatographymass spectrometry for measuring chemicals in saliva of synthetic leather workers. J. Chromatogr. B. 877, 24-32 (2009).

152 Cirimele V, Villain M, Mura P, Bernard M, Kintz P. Oral fluid testing for cannabis: on-site OraLine IV s.a.t. device versus GC/ MS. Forensic Sci. Int. 161, 180-184 (2006).

${ }_{153}$ Pujadas M, Pichini S, Civit E, Santamariña E, Perez K, de la Torre R. A simple and reliable procedure for the determination of psychoactive drugs in oral fluid by gas chromatography-mass spectrometry. J. Pharm. Biomed. Anal. 44, 594-601 (2007).

154 Kankaanpää A, Gunnar T, Ariniemi K, Lillsunde P, Mykkänen S, Seppälä T. Single-step procedure for gas chromatographymass spectrometry screening and quantitative determination of amphetamine-type stimulants and related drugs in blood, serum, oral fluid and urine samples. J. Chromatogr. B Analyt. Technol. Biomed. Life Sci. 810, 57-68 (2004).

155 Cone EJ, Clarke J, Tsanaclis L. Prevalence and disposition of drugs of abuse and opioid treatment drugs in oral fluid. J. Anal. Toxicol. 31, 424-433 (2007).

-156 Strano-Rossi S, Colamonici C, Botre F. Parallel analysis of stimulants in saliva and urine by gas chromatography/mass spectrometry: Perspectives for "in competition" anti-doping analysis. Anal. Chim. Acta. 606, 217-222 (2008).

157 Niessen WMA. Progress in liquid chromatography-mass spectrometry instrumentation and its impact on highthroughput screening. J. Chromatogr. $B$ Analyt. Technol. Biomed. Life Sci. A. 1000, 413-436 (2003).

158 Chang-Kee L, Gwyn L. Current developments in LC-MS for pharmaceutical analysis. Biol. Pharm. Bull. 25, 547-557 (2002).

159 Annesley TM. Ion suppression in mass spectrometry. Clin. Chem. 49, 1041-1044 (2003).

160 Mei H, Hsieh Y, Nardo C et al. Investigation of matrix effects in bioanalytical highperformance liquid chromatography/tandem mass spectrometric assays: application to drug discovery. Rapid Commun. Mass Spectrom. 17, 97-103 (2003).

161 Dams R, Huestis MA, Lambert WE, Murphy CM. Matrix effects in bio-analysis of illicit drugs with LC-MS/MS: influence of ionization type, sample preparation, and biofluid. J. Am. Soc. Mass Spectrom. 14, 1290-1294 (2003).

162 Mortier KA, Clauwaert KM, Lambert EW et al. Pitfalls associated with liquid chromatography/electrospray tandem mass spectrometry in quantitative bioanalysis of drugs of abuse in saliva. Rapid Commun. Mass Spectrom. 15, 1773-1775 (2001).

163 Matuszewski BK, Constanzer ML, ChavezEng CM. Strategies for the assessment of matrix effect in quantitative bioanalytical methods based on HPLC-MS/MS. Anal. Chem. 75, 3019-3030 (2003).

164 Wood M, Laloup M, Samyn N et al. Recent applications of liquid chromatography-mass spectrometry in forensic science. J. Chromatogr. A 1130, 3-15 (2006).

165 Vorce SP, Sklerov JH. A general screening and confirmation approach to the analysis of designer tryptamines and phenethylamines in blood and urine using GC-EI-MS and HPLC-electrospray-MS. J. Anal. Toxicol. 28, 407-410 (2004).

166 Jansen R, Lachatre G, Marquet P. LC-MS/ MS systematic toxicological analysis: comparison of MS/MS spectra obtained with different instruments and settings. Clin. Biochem. 38, 362-372 (2005).

167 Gergov M, Weinmann W, Meriluoto J, Uusiltalo J, Ojanpera I. Comparison of product ion spectra obtained by liquid chromatography/triple-quadrupole mass spectrometry for library search. Rapid Commun. Mass Spectrom. 18, 1039-1046 (2004).

168 Weinmann W, Wiedemann A, Eppinger B, Renz M, Svoboda M. Screening for drugs in serum by electrospray ionization/collisioninduced dissociation and library searching. J. Am. Soc. Mass Spectrom. 10, 1028-1037 (1999).

-169 Weinmann W, Lehmann N, Muller C, Wiedemann A, Svoboda M. Identification of lorazepam and sildenafil as examples for the application of LC/ionspray-MS and MS/MS with mass spectra library searching in forensic toxicology. Forensic Sci. Int. 113, 339-344 (2000).

170 Weinmann W, Stoertzel M, Vogt S, Wendt J. Tune compounds for electrospray ionisation/ in-source collision-induced dissociation with mass spectral library searching. J. Chromatogr. A 926, 199-209 (2001).

171 Saint-Marcoux F, Lachatre G, Marquet P. Evaluation of an improved general unknown screening procedure using liquid chromatography-electrospray-mass spectrometry by comparison with gas chromatography and high-performance liquid chromatography-diode array detection. J. Am. Soc. Mass Spectrom. 14, 14-22 (2003).

172 Venisse N, Marquet P, Duchoslav E, Dupuy JL, Lachatre G. A general unknown screening procedure for drugs and toxic compounds in serum using liquid chromatography-electrospray-single quadrupole mass spectrometry. J. Anal. Toxicol. 27, 7-14 (2003).

173 Marquet P. Progress of liquid chromatography-mass spectrometry in clinical and forensic toxicology. Ther. Drug Monit. 24, 255-276 (2002).

174 Hoja H, Marquet P, Verneuil B, Lotfi H, Penicaut B, Lachatre G. Applications of liquid chromatography-mass spectrometry in analytical toxicology: a review. J. Anal. Toxicol. 21, 116-126 (1997).

175 Tomkins BA, Van Berkel GJ, Jenkins RA, Counts RW. Quantitation of cotinine in nonsmoker saliva using chip-based nanoelectrospray tandem mass spectrometry. J. Anal. Toxicol. 30, 178-186 (2006).

176 Medina JC, Wu N, Lee ML. Comparison of empirical peak capacities for high-efficiency capillary chromatographic techniques. Anal. Chem. 73, 1301-1306 (2001).

177 de Villiers A, Lestremau F, Szucs R, Gelebart S, David F, Sandra P. Evaluation of ultra performance liquid chromatography. Part I. Possibilities and limitations. J. Chromatogr. A. 1127, 60-69 (2006).

178 Al-Dirbashi OY, Aboul-Enein HY, Jacob M, Al-Qahtani K, Rashed MS. UPLC-MS/MS determination of doxazosine in human plasma. Anal. Bioanal. Chem. 385, 1439-1443 (2006).

-179 Berg T, Lundanes E, Christophersen AS, Strand DH. Determination of opiates and cocaine in urine by high $\mathrm{pH}$ mobile phase reversed phase UPLC-MS/MS. J. Chromatogr. A 877, 421-432 (2009).

180 Smink BE, Hofman BJA, Dijkhuizen A et al. The concentration of oxazepam and oxazepam glucuronide in oral fluid, blood and serum after controlled administration of 15 and $30 \mathrm{mg}$ oxazepam. Br. J. Clin. Pharmacol. 66, 556-560 (2008).

- 181 Wood M, Laloup M, Ramirez Fernandez Mdel M et al. Quantitative analysis of multiple illicit drugs preserved in oral fluid by solid-phase extraction and liquid chromatography-tandem mass spectrometry. Forensic Sci. Int. 150, 227-238 (2005).

182 Shiran MR, Hassanzadeh-Khayyat M, Iqbal MZ et al. Can Saliva Replace Plasma for the Monitoring of Methadone? Ther. Drug Monit. 27, 580-586 (2005).

183 Rosas MER, Preston KL, Epstein DH, Moolchan ET, Wainer IW. Quantitative determination of the enantiomers of methadone and its metabolite (EDDP) in human saliva by enantioselective liquid chromatography with mass spectrometric detection. J. Chromatogr. B Analyt. Technol. Biomed. Life Sci. 796, 355-370 (2003). 
184 Kala SV, Harris SE, Freijo TD, Gerlich S. Validation of analysis of amphetamines, opiates, phencyclidine, cocaine, and benzoylecgonine in oral fluids by liquid chromatography-tandem mass spectrometry. J. Anal. Toxicol. 32, 605-611 (2008).

185 Bernhoft IM, Steentoft A, Johansen SS, Klitgaard NA, Larsen LB, Hansen LB. Drugs in injured drivers in Denmark. Forensic Sci. Int. 150, 181-189 (2005).

186 Dams R, Murphy CM, Choo RE, Lambert WE, De Leenheer AP, Huestis MA. LC-atmospheric pressure chemical ionization-MS/MS analysis of multiple illicit drugs, methadone, and their metabolites in oral fluid following protein precipitation. Anal. Chem. 75, 798-804 (2003).

187 Coulter C, Crompton K, Moore C. Detection of phencyclidine in human oral fluid using solid-phase extraction and liquid chromatography with tandem mass spectrometric detection. J. Chromatogr. B Analyt. Technol. Biomed. Life Sci. 863, 123-128 (2008).

188 Moore C, Coulter C, Crompton K, Zumwalt M. Determination of benzodiazepines in oral fluid using LC-MS-MS. J. Anal. Toxicol. 31, 596-600 (2007).
189 Smyth WF, Joyce C, Ramachandran VN, O'Kane E, Coulter D. Characterisation of selected hypnotic drugs and their metabolites using electrospray ionisation with ion trap mass spectrometry and with quadrupole time-of-flight mass spectrometry and their determination by liquid chromatographyelectrospray ionisation-ion trap mass spectrometry. Anal. Chim. Acta. 506, 203-214 (2004).

190 Cheng WC, Ng KM, Chan KK, Mok VK, Cheung BK. Roadside detection of impairment under the influence of ketamineevaluation of ketamine impairment symptoms with reference to its concentration in oral fluid and urine. Forensic Sci. Int. 170, 51-58 (2007).

191 Mortier KA, Renard V, Verstraete AG, Van Gussem A, Van Belle S, Lambert WE. Development and validation of a liquid chromatography-tandem mass spectrometry assay for the quantification of docetaxel and paclitaxel in human plasma and oral fluid. Anal. Chem. 77, 4677-4683 (2005).

192 Kataoka H, Inoue R, Yagi K, Saito K. Determination of nicotine, cotinine, and related alkaloids in human urine and saliva by automated in-tube solid-phase microextraction coupled with liquid chromatography-mass spectrometry. J. Pharm. Biomed. Anal. 49,108-114 (2009).

\section{- Websites}

201 Moore C, Coulter C, Crompton K, Rodrigues R, Vincent M, Soares J. The potential of oral fluid as a specimen in various drug-testing programs www.icadts2007.org/print/poster29_ potentialoralfluid.pdf

202 Roadside Testing Assesment www.rosita.org/

203 DRUID Project www.druid-project.eu/cln_007/sid_910899B FB973A02CB0BDD251C5405983/Druid/ EN/home/homepage__node.html? nnn=true

204 Lacey JH, Kelley-Baker T, Furr-Holden D, Brainard K, Moore C: Pilot Test of New Roadside Survey Methodology for Impaired Driving www.nhtsa.dot.gov/.../NHTSA/Traffic $\% 20$ Injury $\% 20 \mathrm{Control} /$ Articles/Associated $\% 20$ Files/PilotTest_NRSM.pdf 